\author{
MACARENA IBARRA* \\ MARCO BARRIENTOS**
}

\title{
LA MANZANA DE LA CATEDRAL EN SANTIAGo DE CHILE: EXPANSIÓN Y CONTRACCIÓN URBANA, 1874-1913***
}

\begin{abstract}
RESUMEN
Este artículo examina el proceso de desarrollo morfológico de la manzana de la Catedral Metropolitana de Santiago, entre 1874 y 1913. En este período la manzana sufrió radicales transformaciones y alteraciones, que se vinculan a un fenómeno de expansión y contracción urbana que se reflejan en la paulatina redefinición de los contornos interiores y exteriores de los edificios, las transformaciones de las tipologías de edificación y en la densificación urbana. Asimismo, este fenómeno de expansión se manifestó en la hegemonía que alcanzó la Iglesia como propietaria de gran parte de los solares y edificios de la manzana. Se propone que tanto la totalidad de la manzana como sus edificios más emblemáticos -Catedral Metropolitana, Palacio Arzobispal y Parroquia del Sagrario- fueron permeables a factores sociales y políticos, a los propios cambios de la Iglesia como institución, a las continuas transformaciones edilicias y a la modernización de Santiago a partir de las últimas décadas del siglo XIX.
\end{abstract}

Palabras clave: Catedral de Santiago, manzana fundacional, expansión y contracción urbana.

\section{AbSTRACT}

This article examines the process of morphologic development of Santiago's Cathedral block, between 1874 and 1913. During this period the block experienced radical transformations and alterations that were linked to a phenomenon of urban expansion and contraction. This process reflected the gradual redefinition of the interior and exterior contours of the buildings, the transformations of building typologies and of urban densification. This phenomenon of expansion became

* Doctora en Historia urbana, University of Cambridge, Reino Unido. Profesora asistente, Instituto de Estudios Urbanos y Territoriales, Pontificia Universidad Católica de Chile. Correo electrónico: mibarraa@uc.cl

** Arquitecto, Pontificia Universidad Católica de Chile. Correo electrónico: marco.barrientos.m@gmail.com

*** Este trabajo es parte de la investigación sobre la manzana de la Catedral correspondiente al proyecto Fondecyt $\mathrm{N}^{\circ}$ 1090325. Agradecemos especialmente los valiosos comentarios realizados al borrador de este trabajo por el profesor Fernando Pérez. Los autores agradecen también las aclaraciones realizadas por el padre Francisco Javier Manterola, actual vicario pastoral de la Arquidiócesis de Santiago. 
evident with the hegemony reached by the church as owner of most of the buildings on the block. The article proposes that the entirety of the block, as well as most of its emblematic buildings- Metropolitan Cathedral, Archbishop's Palace and the Sagrario Parish - were permeable to social and political factors, to the changes that were affecting the church as an institution, the permanent transformations in the urban fabric and the modernization of Santiago from the last decades of the nineteenth century.

Key words: Santiago's Cathedral, founding block, urban expansion and contraction.

Fecha de recepción: julio de 2010

Fecha de aceptación: marzo de 2011

\section{INTRODUCCIÓN}

El modelo urbanizador implantado en la fundación de la mayoría de las ciudades hispanoamericanas obedeció a un trazado reticular conformado por manzanas y calles ordenadas en base a una geometría regular ${ }^{1}$. Una vez fundada la ciudad de Santiago en 1541, la Corona cedió a la Iglesia los dos solares del costado poniente de la Plaza Mayor, con el fin de erigir allí el templo mayor y una casa para el párroco, mientras los dos solares restantes fueron cedidos a particulares (fig. 1$)^{2}$.

El emplazamiento de la manzana de la Catedral en la ciudad y el uso de sus edificios determinaron su configuración a través del tiempo. Asimismo, la condición particular de la manzana, en la que desde sus orígenes coexistieron dos tipos de propietarios (eclesiales y seculares), jugó un papel central en su posterior desarrollo. Para el caso de las propiedades eclesiales, conviven edificios con un carácter de culto, representado en los templos (Catedral y capilla del Sagrario), dependencias con fines administrativos y residenciales y, paralelamente, otras de carácter eminentemente comercial, concentrado principalmente en el primer piso del Palacio Arzobispal. Similarmente, las propiedades seculares poseen un carácter básicamente habitacional y comercial.

Desde esta perspectiva, el presente artículo examina en qué medida la manzana de la Catedral -como caso atípico dentro de la configuración urbana fundacional, por su ubicación privilegiada en el núcleo de la ciudad y por gozar de una doble condición en sus tipos de uso, religioso y secular- es sometida a las dinámicas y fenómenos transformadores que afectan a la ciudad en su conjunto.

1 Francisco de Solano, Ciudades hispanoamericanas y pueblos de indios, Madrid, Consejo Superior de Investigaciones Científicas, 1990, 20-1.

2 Emma de Ramón señala que la Iglesia Mayor, cuya construcción ya está en curso hacia 1552 , se comienza a utilizar como catedral en 1563, tras la creación de la diócesis en 1561. Véase Emma de Ramón, Obra y Fe. La catedral de Santiago 1541-1769, Santiago, Dirección de Bibliotecas, Archivos y Museos, Centro de Investigaciones Diego Barros Arana, Lom Ediciones, 2002, 38. 
Se sugiere que, pese a sus particularidades, la manzana de la Catedral no se vio ajena a estos cambios. Por el contrario, la manzana estuvo sometida a procesos de transformación urbana similares a los del resto de la ciudad, los cuales fueron cristalizados de manera particular justamente por tratarse de un conjunto que, por un lado, es receptor de las influencias externas -ajustes de los contornos interiores y exteriores de la edificación de la manzana, transformaciones de las tipologías de edificación y densificación urbana- y, por otro, ha estado sometido a las propias fuerzas que actúan desde su interior, toda vez que coexisten allí diversas entidades eclesiásticas -el Cabildo Metropolitano, la Parroquia del Sagrario y el Obispado- ${ }^{3}$.

Entre 1874 y 1913, la manzana de la Catedral sufrió importantes transformaciones y alteraciones, tanto en su interior como en su exterior, que se vinculan a un fenómeno de expansión y contracción morfológica. Así dan cuenta dos de los inventarios de la Iglesia Catedral, el de 1874 y el de 1913, los cuales proporcionan información precisa acerca de la extensión de la propiedad y de sus principales edificios. Más allá de las condiciones propias de la manzana, los procesos de transformación y modernización de Santiago a partir de las últimas décadas del siglo XIX afectaron y permearon no solo su configuración morfológica, sino que desembocaron de manera radical en la expresión de una manzana consolidada formalmente, pero también saturada en su densificación y en su dimensión espacial. Este fenómeno de expansión se manifestó también a través de la hegemonía que alcanzó la Iglesia como propietaria de gran parte de los solares y edificios de la manzana.

Posterior a 1913, una vez alcanzado este apogeo, se iniciará un proceso de declive cuyo período crítico se concentra entre 1930 y 1960 . Se trata de un momento en que la estructura urbana sobre la cual se han producido estas transformaciones se confrontan a un esquema arraigado en el particular trazado fundacional, que, no obstante estar caracterizado por su flexibilidad para dar cabida a una serie de cambios, comenzará a desestructurarse en las décadas siguientes, entrando en un proceso que, paradójicamente a su desarrollo e impulso renovador, estará marcado por una progresiva fragmentación morfológica y ruptura formal (con la irrupción de distintas tipologías edificatorias) y por un abandono y deterioro de gran parte de los edificios del denominado conjunto eclesiástico.

Mas estas transformaciones, tanto en la construcción de las principales edificaciones de la manzana como en los procesos urbanos asociados a su desarrollo, no solo responden a factores de orden formal y material. El fenómeno de expansión y contracción propuesto se debe comprender a la luz de las relaciones, fuerzas y actores que interactúan al interior de la manzana.

Observar tales fuerzas y actores requiere relevar temas tales como en qué medida la construcción o intervención en las distintas piezas de la manzana son parte de una política de planificación de la Iglesia o en qué medida estas intervenciones responden de forma orgánica y espontánea a necesidades prácticas y a las distintas

3 Se entiende por densificación la superficie que ocupan las edificaciones emplazadas en los predios de la manzana. 
coyunturas sociopolíticas o económicas del período. En otras palabras, obliga a examinar cómo dichas fuerzas obedecen a una serie de demandas emanadas del Cabildo Metropolitano, para generar nuevos recintos destinados a la celebración del culto a lo divino y a las funciones administrativas de las instituciones religiosas que allí se encuentran. Ambos factores serán determinantes en las transformaciones espaciales de los edificios y sus recintos, mediante el desarrollo de un proceso gradual de transformación y acomodo de las piezas, las que alcanzarán un mayor grado de unidad arquitectónica y formal. Para 1874, tanto la Catedral, como la capilla del Sagrario y el Palacio Arzobispal se encuentran edificados en forma primaria (en relación a su aspecto actual), pero ya constituyen un conjunto con cierta unidad, especialmente en su fachada principal, hacia la Plaza de Armas.
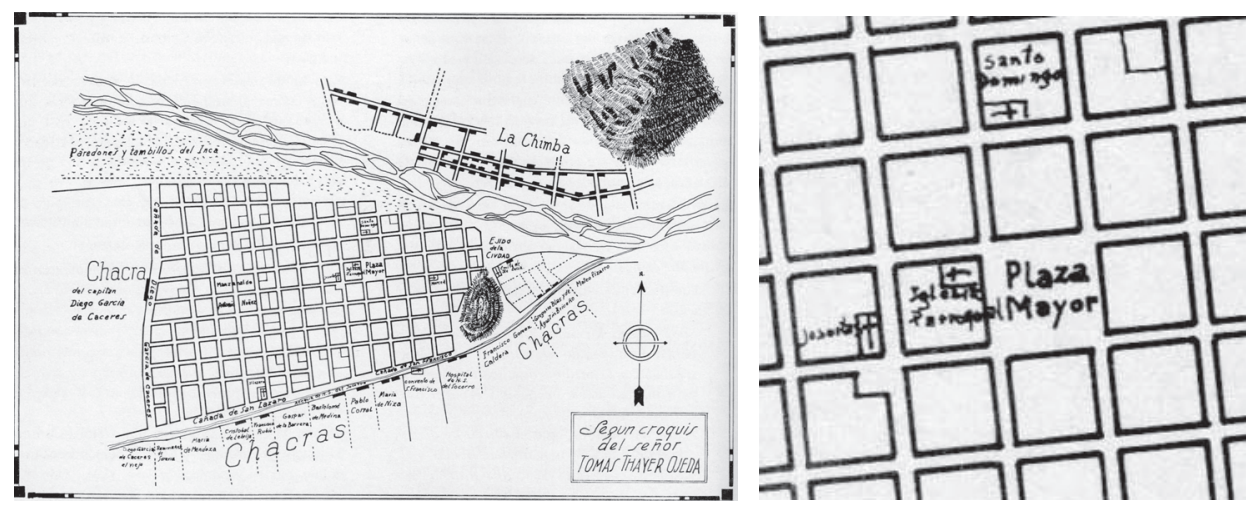

Figura 1. Fundación de Santiago por Pedro de Valdivia, en 1541, según Tomás Thayer Ojeda. Fuente: René Martínez, Santiago de Chile. Los Planos de su historia. Siglos XVI a XX. De Aldea a Metrópoli, Santiago, Ilustre Municipalidad de Santiago, 2007.

La ampliación de los edificios durante este período debió tener correspondencia no solo con el crecimiento demográfico de Santiago, sino también con el crecimiento de la diócesis. La población de la ciudad había aumentado de 70 mil a más de 333 mil habitantes entre 1840 y $1910^{4}$. Además del aumento de fieles en la ciudad, el incremento de la población hizo a la diócesis de Santiago adquirir mayor relevancia. Esto fue determinante para que en 1843, durante el gobierno del arzobispo Manuel Vicuña (1840-1843), el papa Gregorio XVI emitiera la orden de elevarla a arquidiócesis. De este modo, el Obispado de Santiago pasaba a rango de Arzobispado y la Iglesia Catedral al grado de Metropolitana.

La manzana de la Catedral no estuvo ajena a la modernización que experimentaba la ciudad por esos años. El nuevo sistema de alcantarillado -construido en Santiago a partir de 1903- significaba poner fin al antiguo sistema de acequias que recorría los interiores de las manzanas y a la relevancia urbana que las caracteriza-

4 Santiago Poniente: desarrollo urbano y patrimonio (développement urbain et patrimoine), Santiago, Dirección de Obras Municipales de Santiago y Atelier Parisien d' Urbanismo, 2000, 30-3. 
ba al definir en ciertos casos los límites prediales ${ }^{5}$. El sistema de transportes también experimentaba cambios. La inauguración de los tranvías eléctricos en 1900 marcaría el fin del transporte animal y la gradual incorporación de otros medios, hechos que tendrán un impacto en la configuración de la ciudad, de sus calles y pasajes o callejones. Si tradicionalmente el callejón de las caballerizas que dividía el Palacio con la Parroquia había mantenido su importancia y dimensiones con el fin de servir de acceso a los carruajes, en adelante esta función quedaba obsoleta, posibilitando la paulatina uniformidad de la fachada eclesiástica oriente.

Así como los debates en relación a las leyes laicas o a las complejas relaciones Iglesia-Estado permeaban la agenda político cultural de la época, el ánimo de la Iglesia de proyectarse como uno de los pilares institucionales de la república fue también determinante en las transformaciones de la manzana. Paralelamente a los cambios administrativos que implicaba la elevación de diócesis a arquidiócesis, se generan nuevas necesidades que se traducen en la intervención arquitectónica de los edificios eclesiásticos más emblemáticos, reflejando así una monumentalidad acorde con su emplazamiento y jerarquía ${ }^{6}$. Esta mirada cobra especial relevancia en 1910, momento en que Chile celebraba el centenario de su Independencia y los edificios son realzados con el fin de reflejar una imagen de ciudad moderna. La Catedral no estuvo ajena a este espíritu, siendo uno de los edificios remozados para este evento ${ }^{7}$.

Por último, cabe destacar que la historiografía relativa a la Catedral de Santiago no ha terminado por despejar algunas interrogantes que persisten en el tiempo. Tales se refieren especialmente a la desaparecida fábrica colonial (emplazada en sentido Norte Sur); a la autoría del proyecto y la construcción del templo actual; y a la relación de este edificio con el resto del conjunto eclesiástico y de la manzana. La única obra que se ha centrado en forma exclusiva en el estudio del antiguo templo y su conjunto es la desarrollada por Emma de Ramón (2002), que se apoya en una amplia recopilación de fuentes primarias, mientras que el resto se ha concentrado en el examen de su emplazamiento actual. El trabajo de Gabriel Guarda (1997) entrega antecedentes fundamentales para comprender el proyecto y proceso de construcción de la Catedral oriente poniente, constituyéndose en una de las más completas investigaciones sobre esta fábrica.

Adicionalmente, existe un cuerpo de estudios que contribuye con relevante información, descripciones e iconografía del templo en sus distintas etapas, entre los que se encuentran las obras de Carlos Peña Otaegui (1944) y Eduardo Secchi

5 Pese a que el Senado había propuesto utilizar el antiguo sistema de acequias, el sistema de alcantarillado se construye finalmente en el espacio público, tal como sugiriera el arquitecto Ricardo Larraín Bravo. Véase Fernando Pérez Oyarzún, José Rosas y Luis Valenzuela, "Las aguas del Centenario", $A R Q 60$, Santiago, julio de 2005, 73-4.

6 Fernando Retamal, Chilensia Pontificia. Monumenta Ecclesiae Chilensia, Santiago, Ediciones Universidad Católica de Chile, 1998, vol. 1, tomo I, 274-280. Pese a que la elevación formal a dicho rango ocurrió el 13 de marzo de 1843, la correspondencia posterior indica que esta podría haber quedado sin efecto por haber sido presidida por el deán de la Catedral, Alejo Eyzaguirre, al estar enfermo el obispo Vicuña. Esta correspondencia queda en trámite hasta 1888, fecha en que se confirma. Véase Archivo del Arzobispado de Santiago (en adelante AA), Fondo Gobierno, legajo 27, ${ }^{\circ} 1-34,1888$.

7 Macarena Ibarra, "El Centenario: ¿un mito urbano? (Santiago de Chile 1887-1910)", Revista Bicentenario 4:1, Santiago, 2005, 141-162. 
(1941). La obra de Eugenio Pereira Salas (1965) aparece como un texto de consulta obligado, mientras que los trabajos publicados en la investigación inédita Vida de la Catedral (1998) representan importantes esfuerzos de reconstrucción histórica del templo ${ }^{8}$. El trabajo de Marco Antonio León (2005), relacionado a los espacios de conmemoración, constituye un aporte para comprender ciertos ritos y ceremonias religiosas que darán luces sobre el uso de los espacios interiores y exteriores, tanto de la Catedral y su antiguo cementerio como del resto de sus dependencias. Por último, la monografía de Iglesias y Porte (1955) complejiza el desarrollo morfológico del conjunto, destacando las intervenciones de diversos arquitectos y constructores entre 1800 y 1906.

En este marco historiográfico, el presente artículo contribuye al estudio de la Catedral, de su relación con el conjunto eclesiástico, con la manzana y con el entorno urbano ${ }^{9}$. Este artículo instala la discusión de las dinámicas propias que interactúan dentro de esta manzana, en la perspectiva de una reflexión sobre el proceso evolutivo de las manzanas fundacionales de la ciudad. Por último, en una escala más amplia, esta discusión contribuye a posibles relaciones con casos análogos de la región, en un período en que la modernización marcó ciudades con génesis morfológicas y dimensiones geográficas similares, en cuanto a la implantación de un modelo de trazado en el territorio.

\section{IMAGEN DE LA MANZANA DE LA CATEDRAL Y DE SUS EDIFICIOS}

El estudio de la manzana de la Catedral obliga a considerar su sistema de acequias no solo en su carácter de infraestructura sanitaria urbana, sino que también por ser parte de una red ordenadora del damero que coincide, en la mayoría de los tramos, con el trazado de los deslindes. Así, la acequia constituye un elemento de referencia que permite situar y fundamentar el emplazamiento y desarrollo de los diversos edificios que se ubican en el interior de la manzana.

Las acequias han sido representadas en diversos planos y han sido materia de referencia en una serie de documentos históricos. Aun así no existe certeza sobre su ubicación, la que probablemente sufrió alteraciones a través del tiempo. Por ejemplo, la acequia de 1874 es coincidente con el trazado del deslinde que separa el Palacio Arzobispal de la capilla del Sagrario, aun cuando no hay certeza de que sea la misma que existe en el siglo $\mathrm{XVI}^{10}$.

\footnotetext{
8 Seminario de investigación dirigido por Fernando Pérez, Escuela de Arquitectura, Pontificia Universidad Católica, diciembre, 1998.

9 En esta línea, el trabajo de Armando de Ramón constituye una valiosa aproximación a la ciudad colonial a través de un completo registro de las propiedades con la base documental de escribanos. Véase Armando de Ramón, "Santiago de Chile: 1650-1700", Historia 12, Santiago, 1974.

10 Esta ubicación se fundamenta en los documentos contenidos en Memorial (Reservado) de la Comisión nombrada por el V. Cabildo Metropolitano de Santiago de Chile para estudiar las cuestiones pendientes entre el I.S. Arzobispo y la Iglesia sobre el Palacio Arzobispal, Santiago, s.n., 1892, y se puede corroborar con los hallazgos arqueológicos realizados a partir de las excavaciones para la construcción de la estación del metro Plaza de Armas, registradas en 2001.
} 
El aporte documental y el plano adjunto del Memorial (Reservado) de la Comisión nombrada por el V. Cabildo Metropolitano de Santiago de Chile para estudiar las cuestiones pendientes entre el I.S. Arzobispo y la Iglesia sobre el Palacio Arzobispal permite reconstruir parte del curso de la acequia en este período (fig. 2) ${ }^{11}$. Esta fuente indica que, por el oriente de la manzana, el curso se situaba entre el muro norte del Palacio Arzobispal y el muro sur de la capilla del Sagrario, en lo que antiguamente correspondía a un callejón de acceso a las cocheras y caballerías (fig. 2 C), mientras que en el costado poniente se localizaba la salida de la acequia (fig. 2, C3), por debajo del comedor de la sacristía de los canónicos (fig. 2, r). Así, este plano identifica los extremos de la acequia en el borde oriente y poniente de la manzana para la década de 1890 .

Una segunda fuente permite precisar el primer tramo interior de la acequia. Un informe fechado en 1885 da cuenta sobre el mal estado del muro norte del Palacio Arzobispal y hace referencias a la ubicación de la acequia,

“[...] que atraviesa oblicuamente en dirección de oriente a poniente, el patio que separa el Palacio Arzobispal de los edificios de la Catedral, dista de la muralla, en la parte en que se encuentra la rasgadura 2.80 metros, i en el extremo poniente del edificio, es decir en los 16,80 metros de muralla, cinco metros [...]"12.

La mencionada "rasgadura" se refiere al acceso desde la Plaza de Armas, es decir, justamente al área contenida entre el muro norte del Palacio y el muro sur del Sagrario (fig. 3 tramo a1/a2). Con esta información es posible reconstruir cuál habría sido su ubicación exacta en la primera parte de la manzana y cuantificar con precisión las medidas y su curso en toda la extensión correspondiente a su inicio, desde el frente oriente de la manzana hasta el fondo del sitio del Palacio Arzobispal (fig. 3, tramo a2 y a3).

Una tercera fuente permite determinar cómo seguía el curso de la acequia en el tramo a4-a5 de la figura 3. Se trata de un plano del proyecto de servicios sanitarios de la propiedad denominada Casas del Cabildo, vecina por el poniente del Palacio Arzobispal y por el sur de la Catedral (fig. 4) ${ }^{13}$. Este plano grafica, entre otros aspectos técnicos, la acequia que recorría el fondo del sitio, paralela al deslinde común con las oficinas y sala capitular de la Catedral (fig. 4, línea punteada). Se trata de una valiosa fuente, en cuanto proporciona con exactitud no solo la posición de la acequia en referencia a las construcciones de la propiedad, sino que además dimensiona su ancho y largo.

$11 \quad$ Ibid., 81.

12 AA, Fondo gobierno, legajo 28, $\mathrm{n}^{\circ}$ 57, El arquitecto Carlos Tegemoller firma e informa sobre el estado de la muralla, 27 de diciembre, 1885.

13 Archivo Técnico de Aguas Andinas, Plano sanitario casas del Cabildo, ${ }^{\circ}$ 2073, Santiago, 1910. 


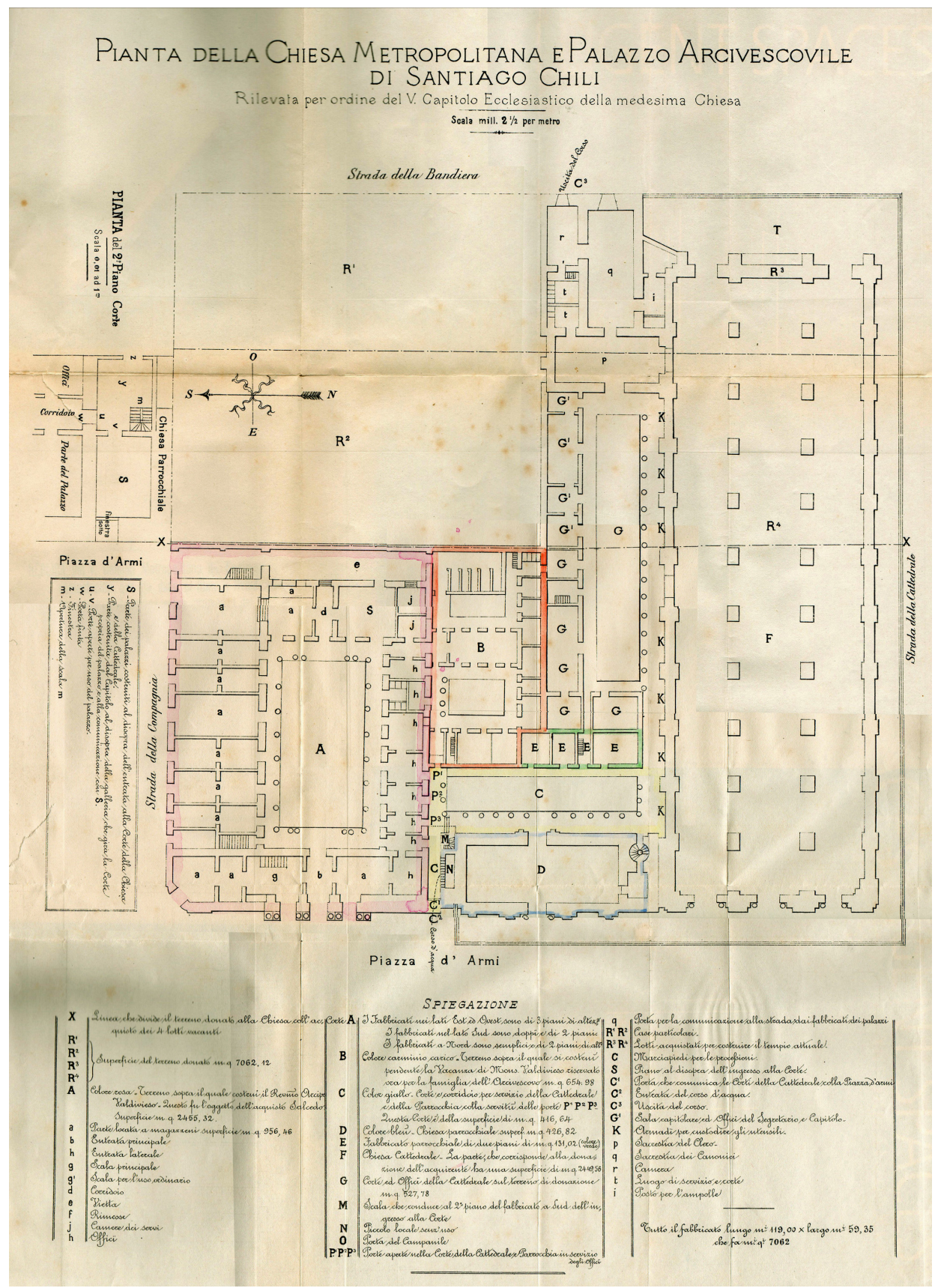

Figura 2. Plano de la manzana de la Catedral, 1892.

Fuente: Memorial (Reservado) de la Comisión nombrada por el V. Cabildo Metropolitano de Santiago de Chile para estudiar las cuestiones pendientes entre el I.S. Arzobispo y la Iglesia sobre el Palacio Arzobispal, Santiago, 1892. 


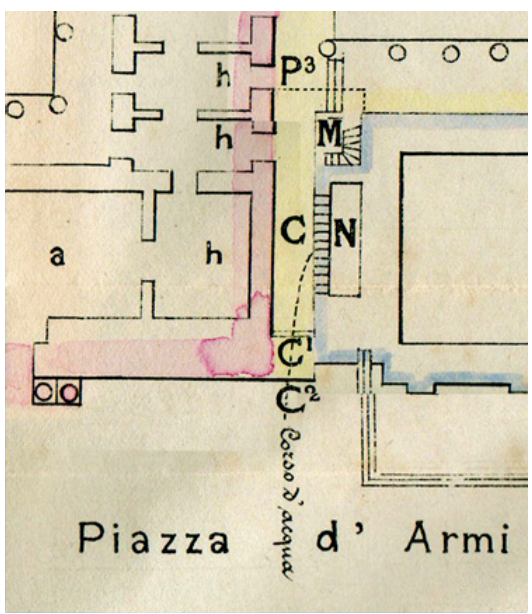

Figura 2a. Detalle Fig. 2. Acceso acequia (c1/c2) entre acequia (c3) bajo comedor Sagrario y el Palacio Arzobispal.

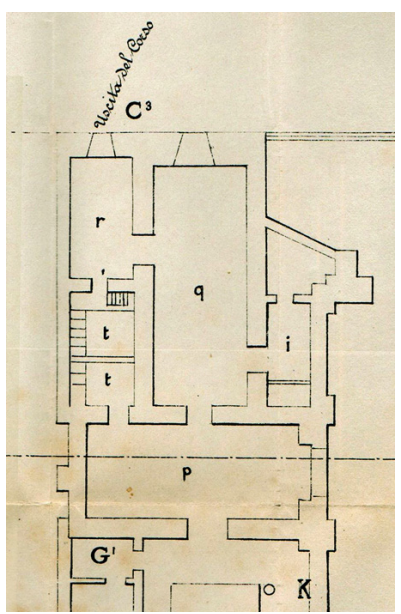

Figura 2b. Detalle Fig. 2. Salida Canónicos (r).

De este modo, teniendo una primera visión documentada de ciertos trazos de la acequia de fines del siglo XIX y principios del XX, es posible aventurar y proponer los tramos sobre los que no hay antecedentes. En este caso son las líneas punteadas que se grafican en el plano de la reconstrucción del curso de las acequias (fig. 3), en los tramos a3/a4 y a5/a6/a7, que básicamente unen los puntos de los tramos documentados, y se alinean con los deslindes de las propiedades, siguiendo la lógica de la división predial. Esta primera aproximación propone un recorrido interior que, lejos de ser regular, ortogonal y simétrico, responde más bien a la irregularidad de una geometría determinada por los deslindes con quiebres y líneas anguladas que se van adecuando a las situaciones particulares de la manzana.

Si esbozar el curso de la acequia y sus características permite sugerir algunos rasgos de la manzana para este período, definir los contornos de la manzana aparece también como tarea central. En perspectiva de los fenómenos de contracción y expansión, cabe destacar que se observan alteraciones en las líneas perimetrales de las construcciones. Más allá de la línea demarcada por el propio edificio, las gradas que rodean los frentes oriente, norte y poniente de la Catedral merecen especial atención.

En el inventario de 1875, el terreno que pertenecía a la Iglesia Catedral, incluía el ancho de las gradas de la calle Catedral por el norte y las gradas por calle Bandera por el oriente. Por el sur, en tanto, el terreno era irregular y colindaba con propiedades particulares ${ }^{14}$.

14 Archivo de la Catedral (en adelante AC), Inventario de la Santa Iglesia Metropolitana de Santiago de Chile, 12 de marzo, 1875. De acuerdo a este inventario, el terreno que pertenecía a la Iglesia Catedral medía por el costado oriente, incluyendo el ancho de las gradas de la calle de la Catedral, 72,90 metros, por su costado norte, incorporando el ancho de la grada que daba a la calle de la Bandera, 117,60 metros, por el poniente, la extensión era de 52,20 metros, mientras que por el sur el terreno era irregular, en cuanto las propiedades seculares se internaban 19 metros al norte, abarcando de este a oeste 84,60 metros. 


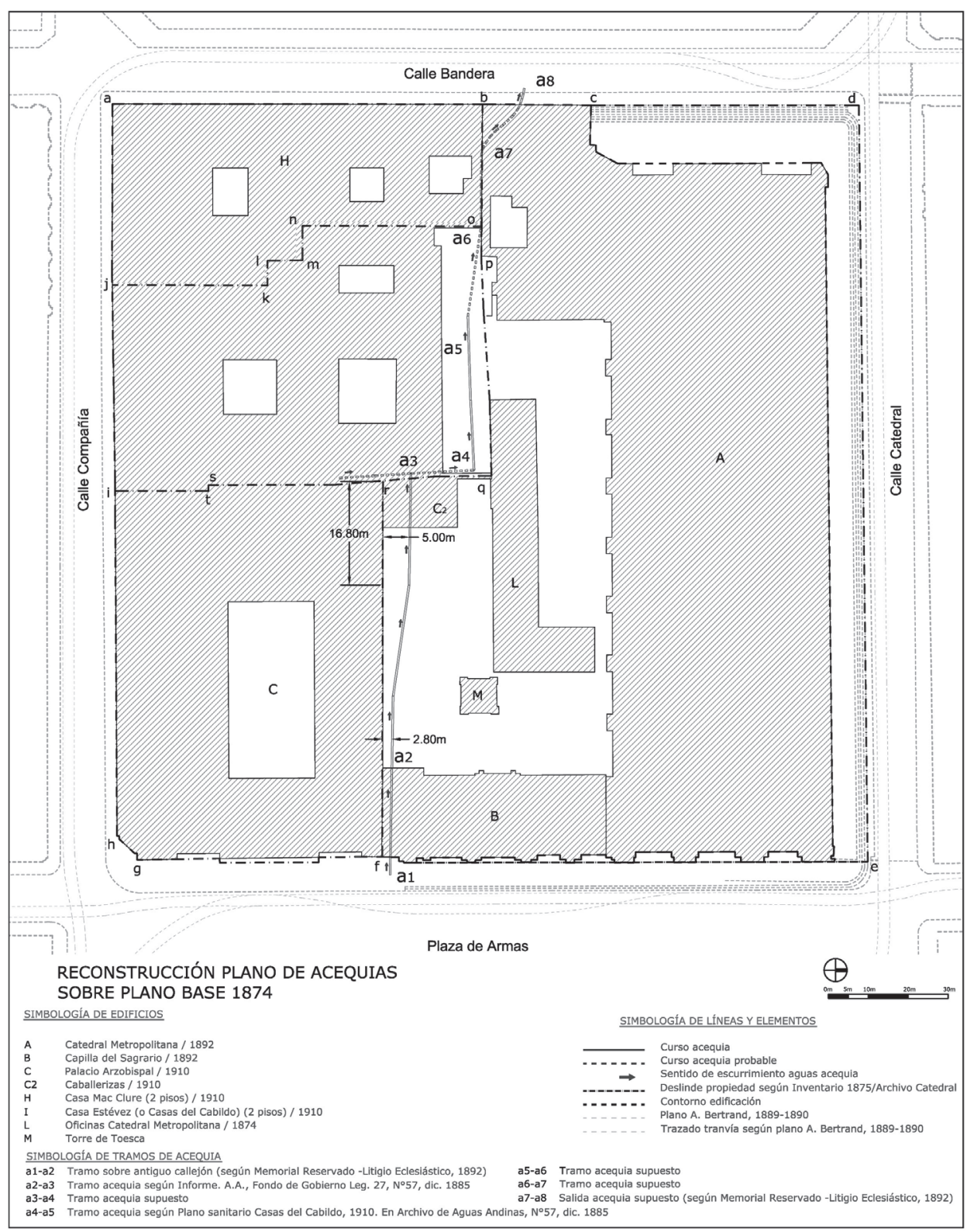

Figura 3. Reconstrucción del plano de la manzana hacia 1840 con los cursos de las acequias. Plano elaborado por Marco Barrientos, 2010. 


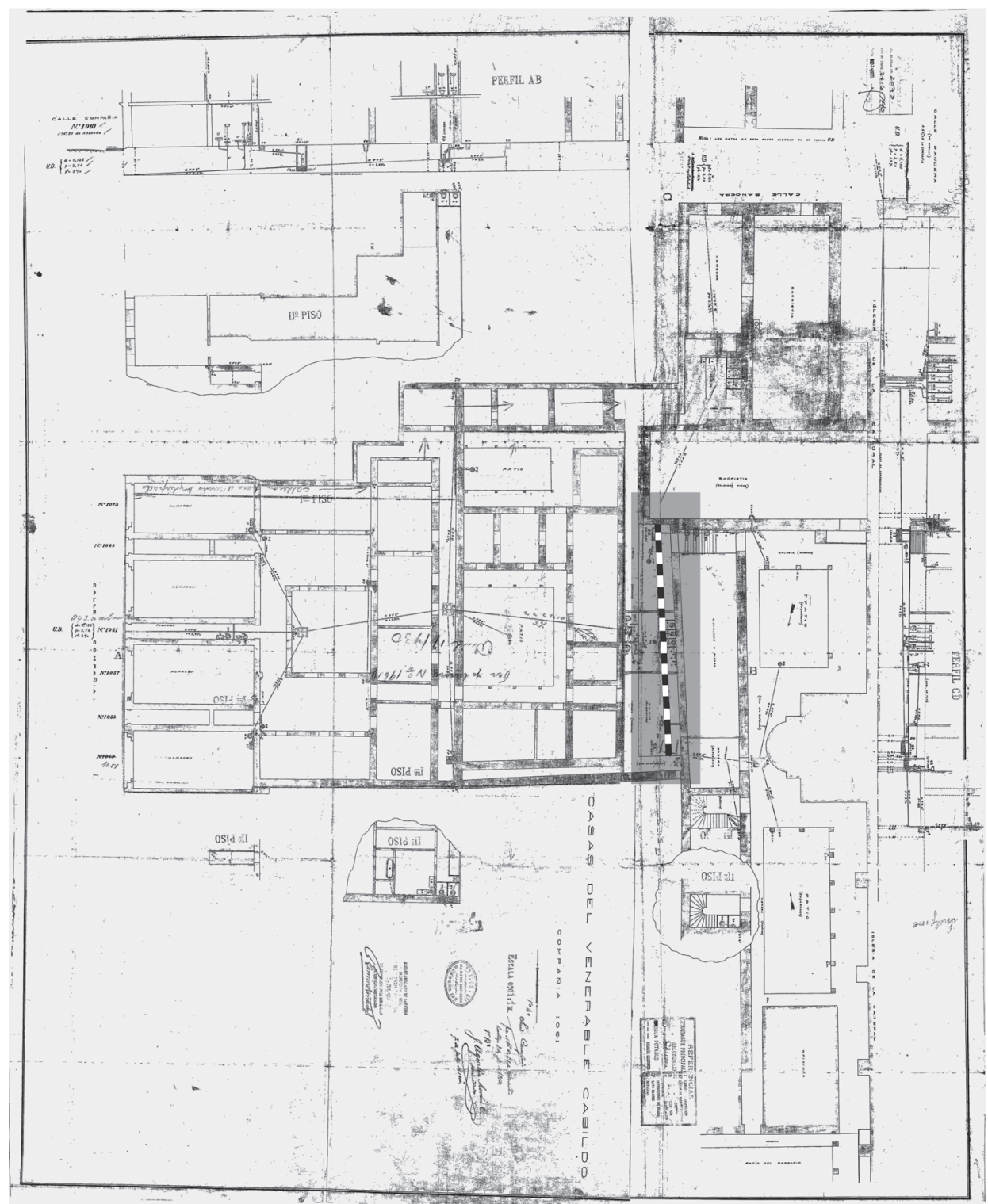

TRAZADO DE ACEQUIA

Figura 4. Plano sanitario de propiedad ubicada en calle Compañía 1061, Santiago, 1910 (intervenido por los autores). Fuente: Archivo Técnico de Aguas Andinas, Plano proyecto sanitario Casas del Cabildo, $\mathrm{N}^{\circ}$ 2073, Santiago, 1910. 
Más allá de la línea de edificación que demarcaba la propiedad de la Iglesia Metropolitana, sus límites (norte, oriente y poniente) se veían incrementados por la posición de las gradas, lo que significaba un incremento de la superficie tradicionalmente estimada para su propiedad (fig. 3). Se trata entonces de un límite "virtual" de la Catedral, pero que puede ser fundamental para precisar el significado de ciertos planos históricos, así como el emplazamiento del antiguo templo. Por ejemplo, un aspecto de interés es la relación de este borde con el emplazamiento de la Catedral del siglo XVIII que grafica el cronista francés Francois Frézier, desalineada en relación a las líneas de edificación del resto de las manzanas circundantes (figs. 5 y $5 \mathrm{a}$ ).

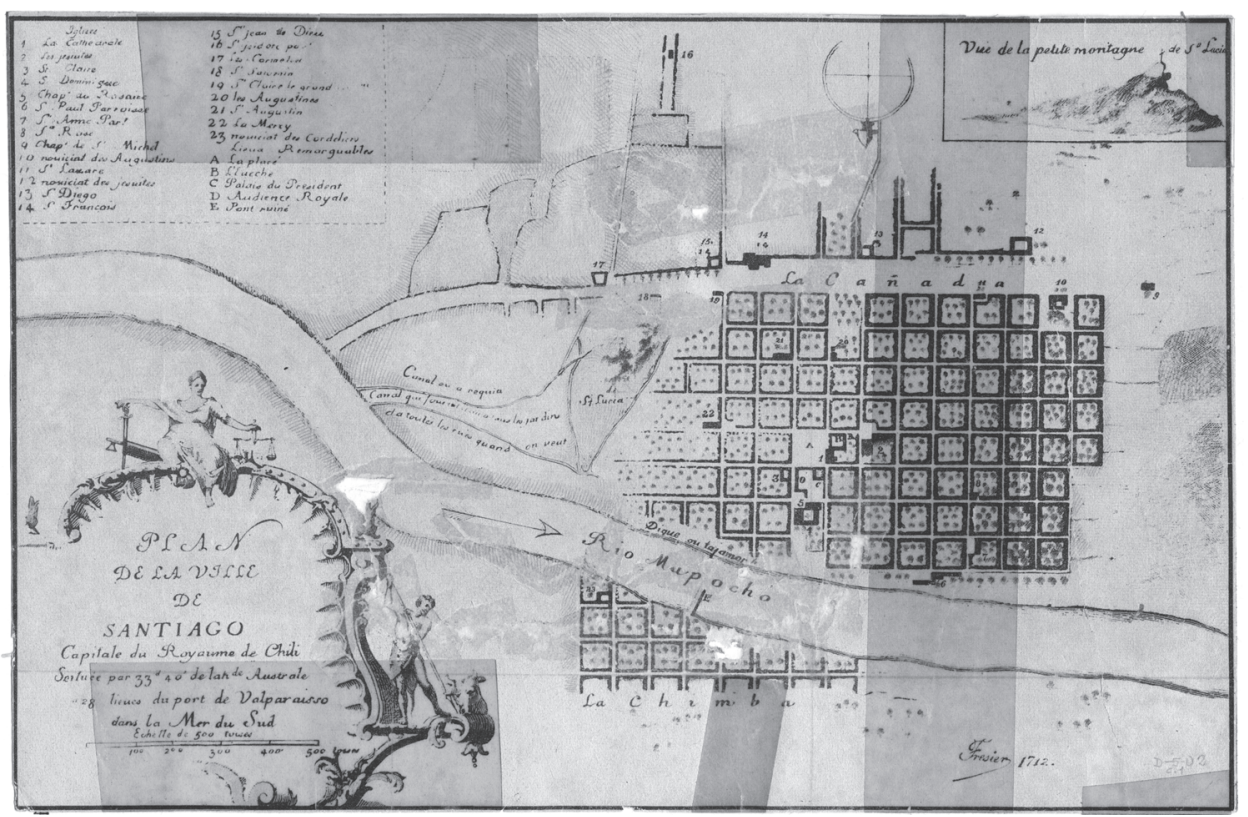

Figura 5. Plano de Santiago por Frezier.

Fuente: Francois Frézier, Relation du Vogage a la Mer du Sud aux cotes du Chili et du Perou. 1712, 1713, 1714, París, 1732.

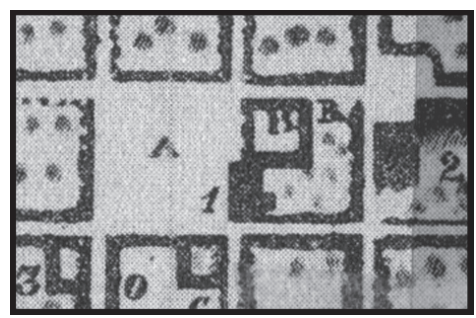

Figura 5a. Detalle del plano de Francois Frézier. A. Plaza / B. Casa Obispo / 1. Catedral
Este límite "virtual" de la propiedad de la Catedral comenzará a desdibujarse producto de los retranqueos que sufrieron las fachadas en comparación con las preexistentes.

En el caso de la fachada poniente, esta contracción responde a la necesidad de dar solución al problema que surge en el tratamiento de la diferencia de nivel producido por la pendiente del valle de Santiago. Así, mientras la fachada que enfrenta la calle Bandera se retrae, por otro lado se genera una franja destinada a vereda. La 
diferencia de nivel (dos metros aproximadamente) se corrige mediante dos cuerpos de gradas que coronan el acceso al templo desde las naves laterales. Desde la calle Compañía hacia el oriente, se observa la uniformidad propia de la configuración de edificios de fachada continua, lo que evidencia la citada contracción.

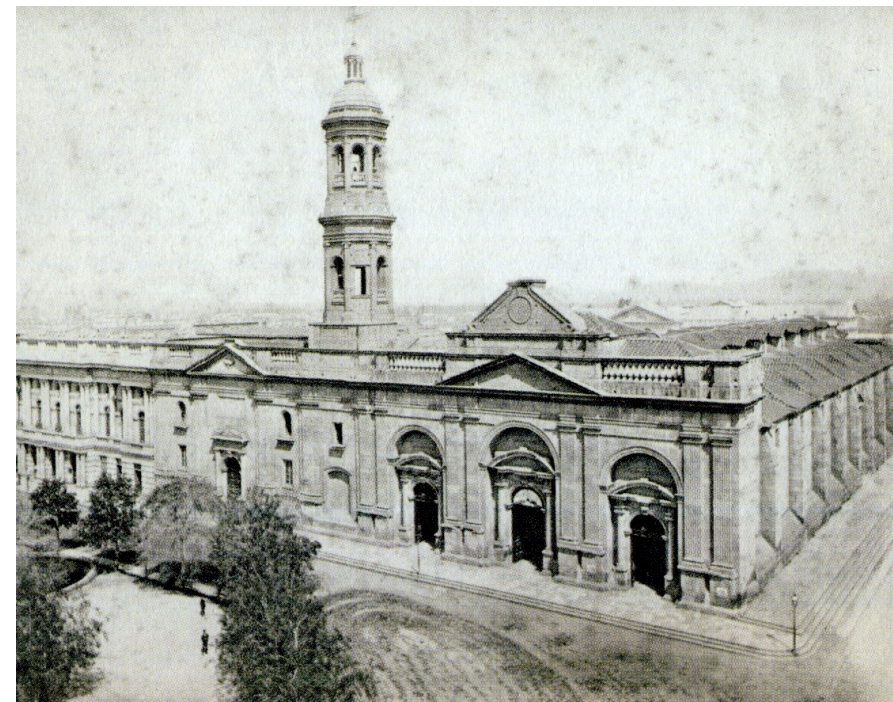

Figura 6. Fotografía de las fachadas norte y oriente de la manzana de la Catedral hacia 1875. Fuente: Museo Histórico Nacional, Plaza de Armas de Santiago, Santiago, 1944.

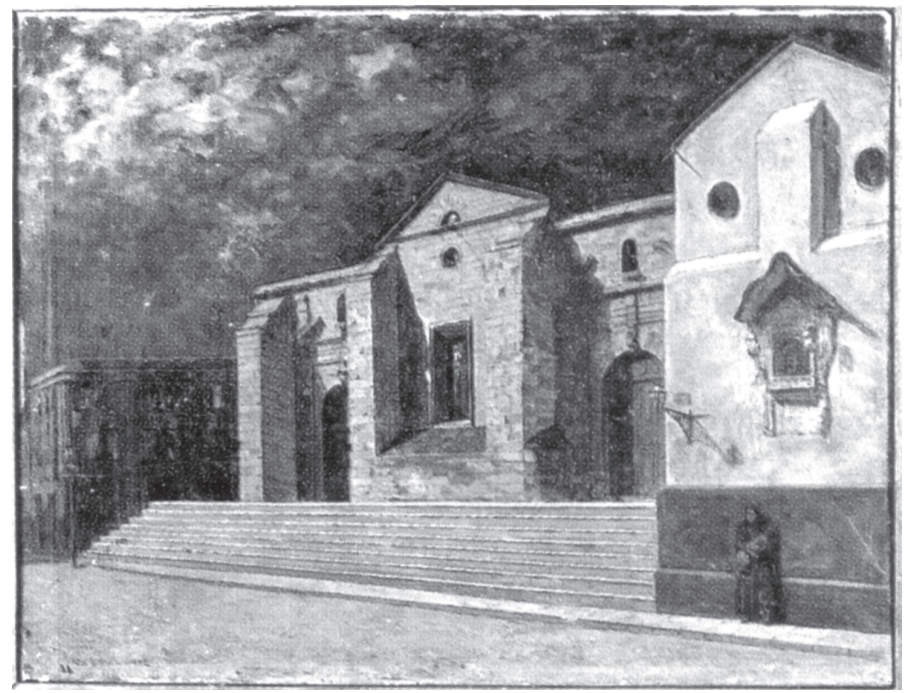

Figura 7. Óleo de la fachada poniente de la Catedral anterior a la intervención de Cremonesi. Fuente: Augusto Iglesias y Enrique Porte, La Catedral de Santiago de Chile. Estudio monográfico, Instituto de Historia de la Arquitectura, Santiago, s.n., 1955. 
Hacia 1840, la manzana contaba con la mayoría de sus edificios perimetrales en un importante estado de avance de construcción. Tras la intervención de Toesca (1780-1799), quien concluyó el último tercio del templo (costado oriental), transcurre casi un siglo de intervenciones más bien aisladas que antecedieron a las radicales transformaciones de Ignacio Cremonesi a partir de $1897^{15}$. Durante gran parte del siglo XIX, las discusiones acerca de las obras en la Catedral estuvieron animadas por la idea de que se trataba de un templo en mal estado e inconcluso ${ }^{16}$.

La capilla del Sagrario, en tanto, había sido inaugurada en 1863, según sugiere un documento que reproduce un conflicto entre esta entidad y la Catedral a raíz del uso de las campanas ${ }^{17}$.

Además de la Catedral y de la Parroquia del Sagrario, el Palacio Arzobispal era una importante pieza del conjunto eclesiástico que completaba todo el frente occidental de la Plaza de Armas, a pesar de que su condición, carácter y destino estaban vinculados a actividades profanas (comercio y habitación), apartándose del carácter netamente religioso y de culto de los otros dos templos.

Fue precisamente en esta década cuando el Palacio se concluyó. Las obras, iniciadas en 1847, proyectadas y supervisadas por Vicente Larraín, se suspendieron al poco tiempo por falta de fondos, pero se retomaron en 1850 con algunas interupciones para encaminarse en su etapa final a mediados de la década de 1860. Si bien no se ha podido establecer cuál fue el grado de intervención del arquitecto francés Brunet de Baines, se sabe que retomó las obras iniciadas por Larraín y modificó algunas soluciones formales en la fachada ${ }^{18}$. Como sea, hacia 1872 el Palacio Arzobispal estaba prácticamente concluido, luego de tres décadas de continuos esfuerzos por reunir los fondos necesarios.

Resulta interesante destacar cómo se había concebido en sus inicios esta empresa de construcción. Durante el gobierno del arzobispo Vicuña, el Cabildo Metropolitano había puesto en conocimiento el mal estado de la existente Casa Episcopal. Por este motivo, el obispo y el Cabildo Metropolitano acuerdan su reedificación, la que contempla su arriendo con el fin de financiar los altos costos que esta tenía ${ }^{19}$. En este sentido, el Cabildo había determinado priorizar la edificación del costado de la calle Compañía, de forma tal que se pudieran arrendar los locales comerciales ubicados en ese costado y en el frente de la Plaza de Armas. Debido a que ambas construcciones eran de dos pisos, se debía reforzar el denominado cañón de piezas del costado norte del Palacio, con el fin de poder concluir las tiendas del centro al tiempo que se lograra la estabilidad requerida para el soporte estructural del edificio:

15 Eduardo Secchi, Arquitectura en Santiago. Siglo XVII a siglo XIX, Santiago, Comisión del Cuarto Centenario de la Ciudad, 1941, 75-6.

16 Particularmente se da cuenta del mal estado de los techos y de la torre pendiente para su frontis. Véase AA, Fondo Gobierno, legajo 28, n 40, 1845-1849 y AA, Fondo Gobierno, legajo 27b, $\mathrm{N}^{\circ} 57 \mathrm{a}, 1858-1882$.

17 AC, Inventario de la Santa Iglesia Metropolitana de Santiago de Chile, 1874

18 AA, Fondo Gobierno, legajo 27, $\mathrm{n}^{\circ} 43,30$ de octubre, 1880.

19 AA, Fondo Gobierno, legajo 28b, No 53,24 de julio, 1841. 
“[...] los pisos bajos de ambos cañones [norte y sur] son alquilables pues forman una prolongación de los almacenes de la calle de la compañía i plaza con que confinan, i sus pisos altos son de absoluta necesidad para el arriendo de la parte alta de los cañones que caen a la plaza i calle de la compañía" 20 .

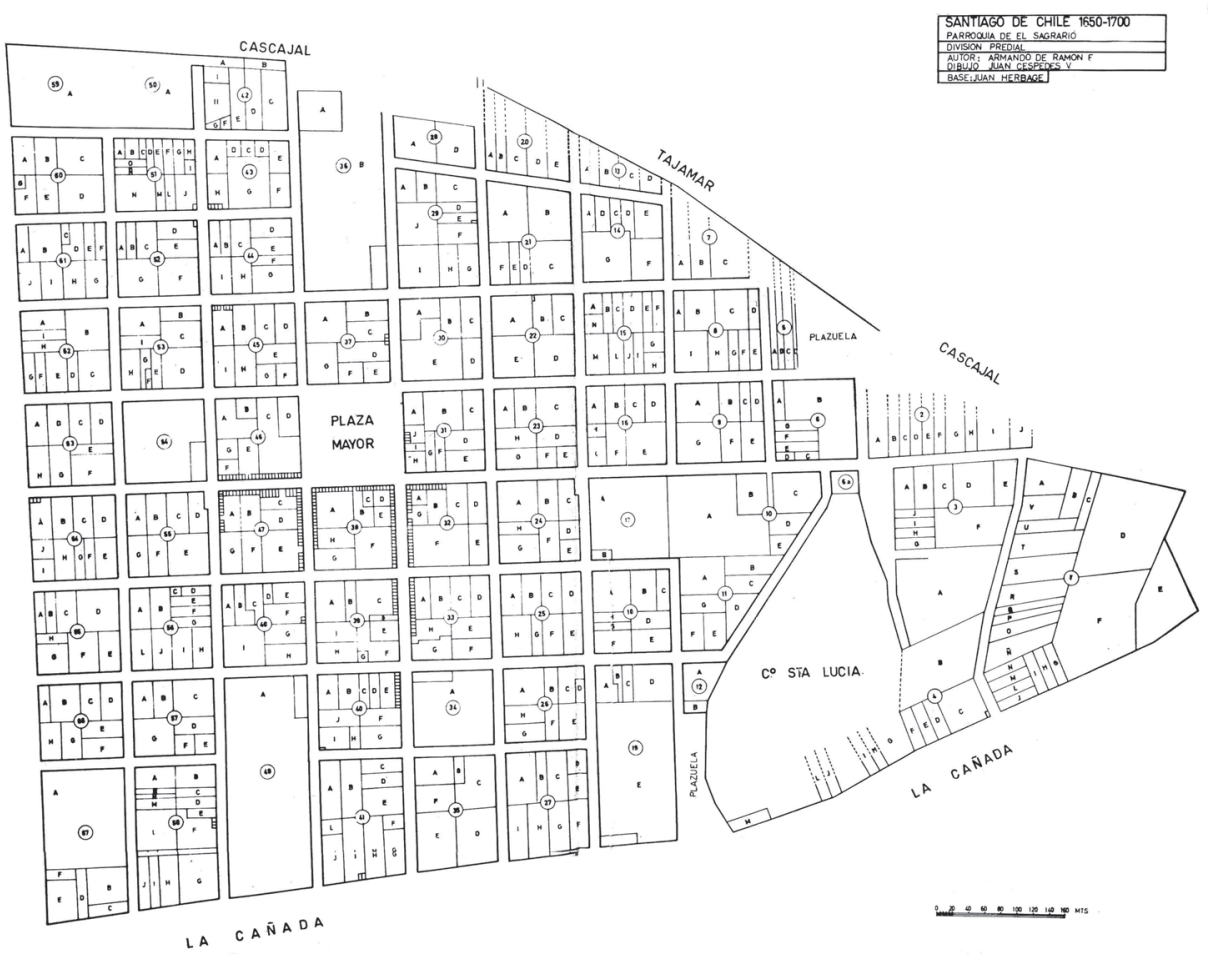

Figura 8. Plano de división predial de Santiago entre 1650 y 1700 . El área sombreada representa la zona en torno a la manzana de la Catedral.

Fuente: Armando de Ramón, Santiago de Chile: 1650-1700, Historia 12, Santiago, 1974.

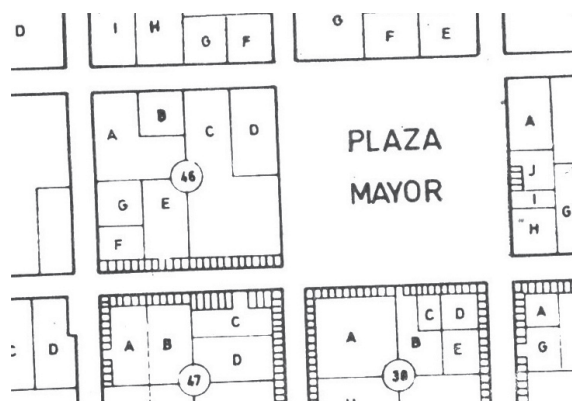

Figura 8a. Detalle del plano de división predial de Santiago entre 1650 y 1700.
Simbología de manzana 46:

A. Propiedad particular hasta 1747

B. Propiedad particular hasta 1747

C. Terreno correspondiente al cementerio de la Catedral y al Obispado. En el costado sur del terreno se observan locales comerciales.

D. Propiedad de la Catedral

E. Propiedad particular con locales comerciales

F. Propiedad particular con locales comerciales

G. Propiedad particular 
La privilegiada ubicación de la manzana en el corazón de la ciudad la dotó de un valor comercial desde sus orígenes. En esta línea, el estudio de Armando de Ramón Santiago de Chile, 1650-1700 muestra cómo el costado sur de la manzana, hacia la calle Compañía, tenía en toda su extensión tiendas y oficinas durante el siglo XVII ${ }^{21}$. Conviene recordar que ante la constante estrechez económica de la Iglesia, las posibilidades comerciales de sus dependencias aparecían más que como una oportunidad, como una necesidad.

Los principales edificios eclesiásticos -la Catedral, el Sagrario y el Palacioactuaron como contenedores del desarrollo del interior de la manzana, obligando a concentrar su crecimiento hacia el vacío interior. Al centro de la manzana existía un gran patio con algunas construcciones aisladas, que se ubicaban a lo largo del deslinde sur de la propiedad, incluida la antigua torre que servía tanto al Sagrario como a la Catedral (fig. 14). En julio de 1845 el Cabildo Eclesiástico acordó reedificar el cañón de piezas que existían en el costado sur de la Iglesia, al mando de Vicente Larraín. El arquitecto propuso además dividir en dos el gran patio de los naranjos, que iba desde la sacristía del clero hasta la capilla del Sagrario, el que sería separado por oficinas destinadas a la Parroquia del Sagrario (fig. 13) 22 $^{22}$

Una edificación importante emplazada en el interior de la manzana (actual patio del Sagrario) durante este período corresponde a la antigua torre, cuya construcción y diseño son atribuidos a Joaquín Toesca. Esta torre era el único elemento vertical que servía para el llamado de los fieles, tanto para la Parroquia como para la Catedral. El mal estado de su construcción y su condición inicial de torre provisoria llevaron a su demolición en 1875, despejando así la constante preocupación por un eventual derrumbe. Más aún, la solicitud del arzobispo a Juan Murphy para evaluar los daños del temblor ocurrido el 27 de septiembre de 1874 da cuenta de que para ese año el proyecto de construir una torre en el frontis del Sagrario ya estaba en desarrollo. Finalmente, fue el mismo Murphy quien la diseñó y construyó en 1875.

La existencia y posterior demolición de la torre de Toesca fue determinante en los cambios que experimentó la manzana durante el período. Es necesario, por tanto, identificar su ubicación y algunos rasgos formales de este cuerpo. Su emplazamiento se ha podido determinar gracias al aporte de fuentes iconográficas y documentales que refieren la ubican en función de los demás edificios eclesiásticos.

Resulta de especial interés el croquis de Mauricio Rugendas, en el que se representa más de la mitad del cuerpo vertical de la torre (fig. 9). De fondo se aprecia la Catedral con sus contrafuertes, techumbre y fachada hacia la plaza y, en primer plano, las casas del obispo, de carácter colonial, con pilar de esquina y de baja altura. La torre, en tanto, se ubica al interior de estas construcciones y destaca como campanario y como elemento vertical (fig. 9).

21 Armando de Ramón, op. cit., 242-5.

22 AA, Fondo Gobierno, legajo 28, n 40, 12 de agosto, 1845. 


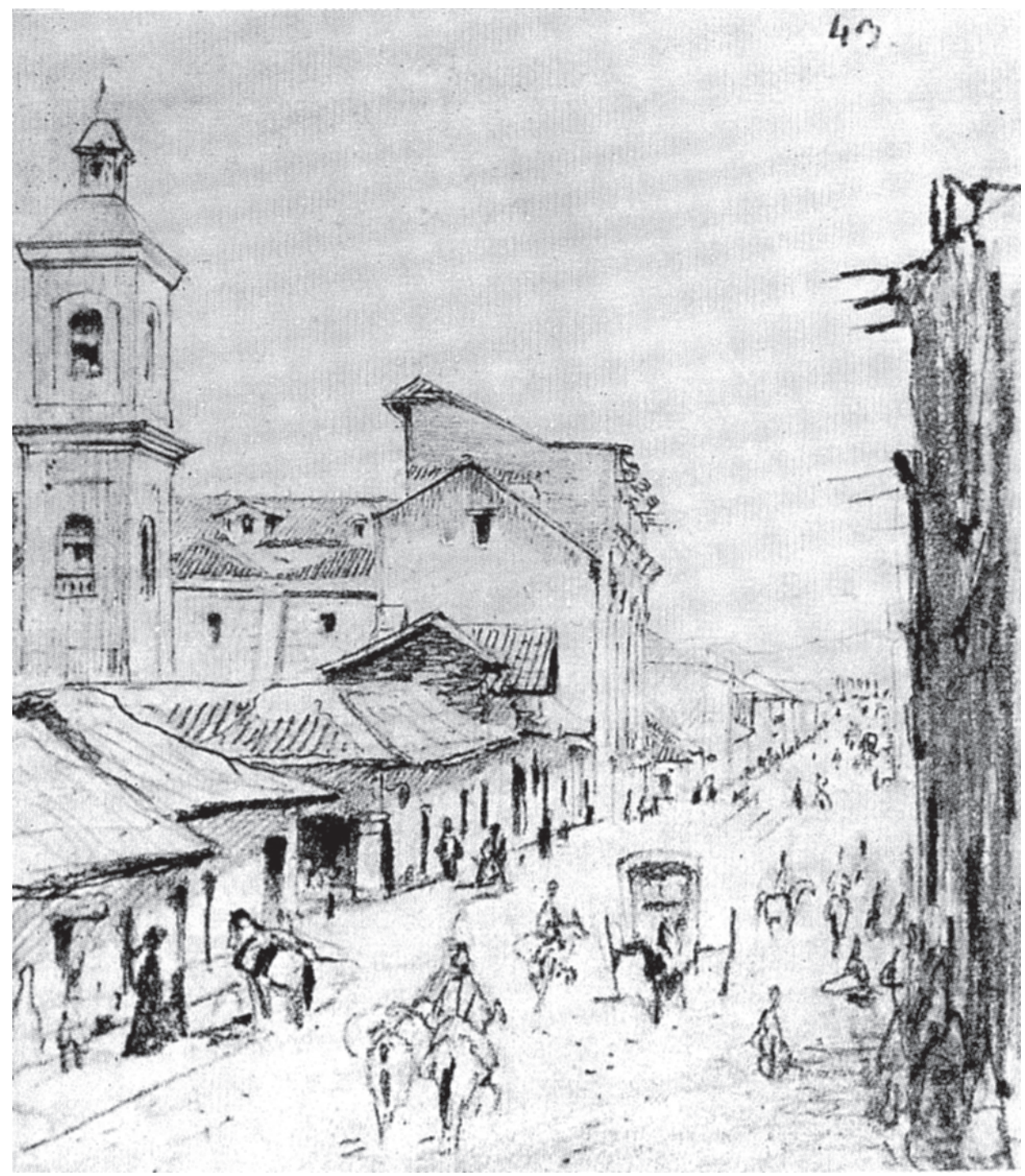

Figura 9. Dibujo de Mauricio Rugendas calle Ahumada hacia Plaza de Armas, sin fecha.

Fuente: Gabriel Guarda, El arquitecto de La Moneda, Joaquín Toesca, 1752-1799, Santiago, Ediciones Universidad Católica de Chile, 1997.

Otras fuentes iconográficas posteriores muestran la misma torre desde una vista frontal desde la Plaza de Armas, donde se aprecia la fachada eclesiástica parcialmente constituida. En una fotografía que corresponde a la década de 1850, aparece la torre de Toesca situada detrás de la capilla del Sagrario (fig. 10). Al costado de la capilla, se aprecia la entonces casa del obispo, distinta a su aspecto actual y, en el fondo, la torre y cúpula de la iglesia de la Compañía, incendiada en 1863. 


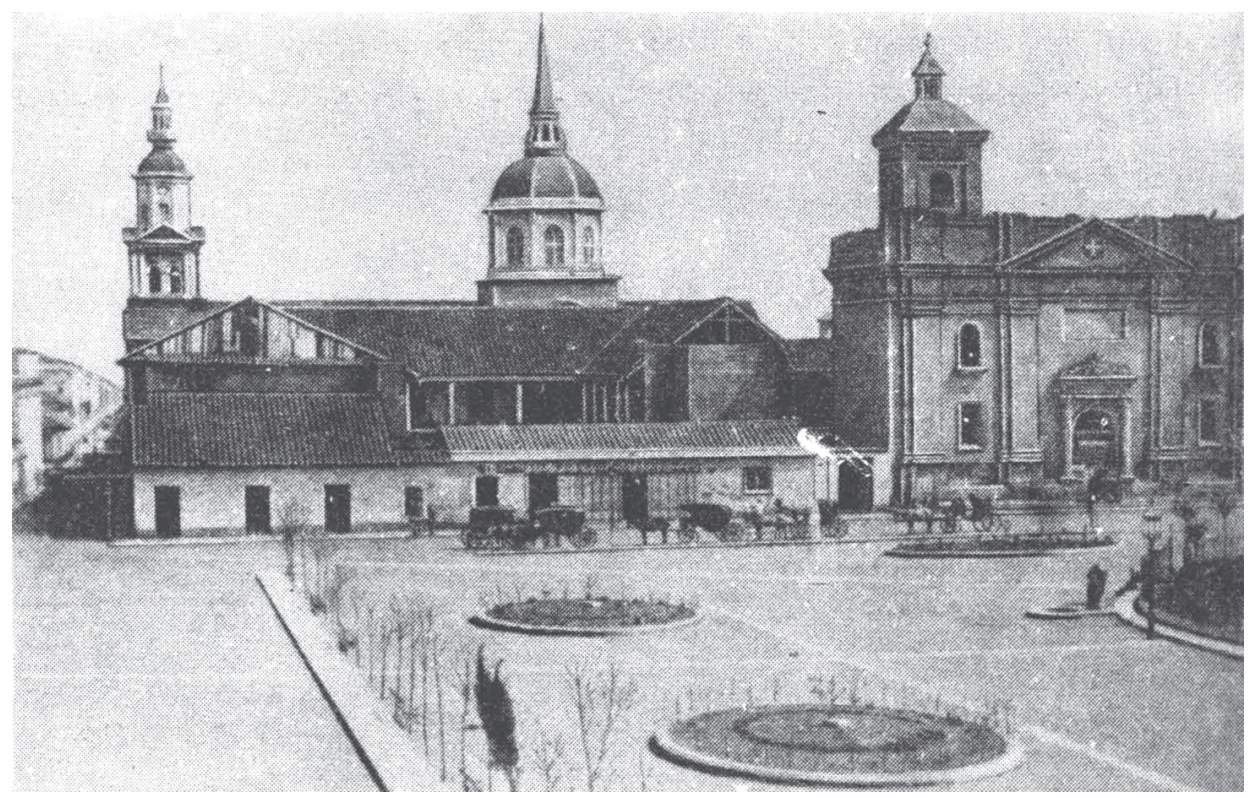

Figura 10. Fotografía de la fachada eclesiástica hacia 1850.

Fuente: Carlos Peña Otaegui, Santiago de Siglo en Siglo, Santiago, Zig-Zag, 1944.

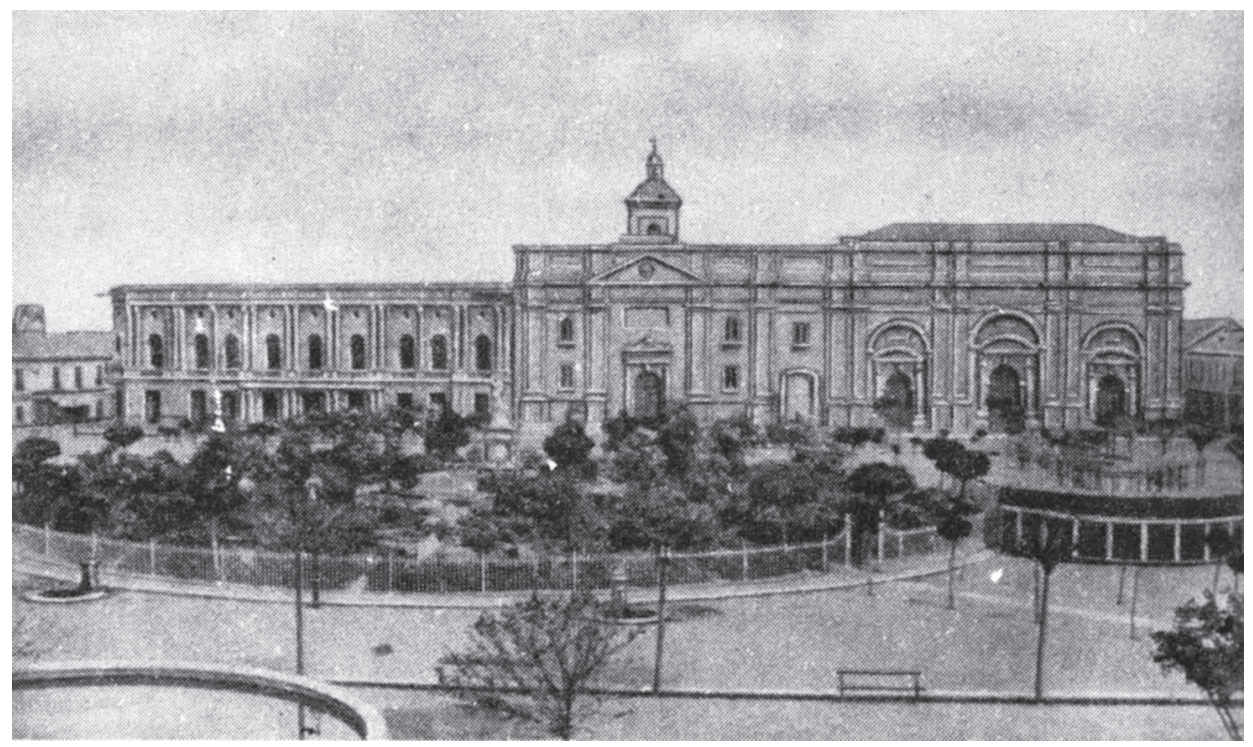

Figura 11. Fotografía de la fachada eclesiástica hacia 1870.

Fuente: Carlos Peña Otaegui, Santiago de Siglo en Siglo, Santiago, Zig-Zag, 1944. 
En una segunda fotografía del costado oriente de la manzana, cuya data correspondería al año 1870 , se aprecia la fachada eclesiástica prácticamente concluida en toda su extensión. Solo falta la conclusión de la balaustrada que corona la parte superior de la fachada del Palacio Arzobispal y que alinea las cornisas de los tres edificios (fig. 11). En esta imagen se observa, además del orden formal de la fachada, la horizontalidad de la edificación y, aunque en segundo plano, la vieja torre de Toesca, que asoma como único elemento vertical. La torre se aprecia prácticamente en el mismo eje de la puerta de acceso a capilla del Sagrario.

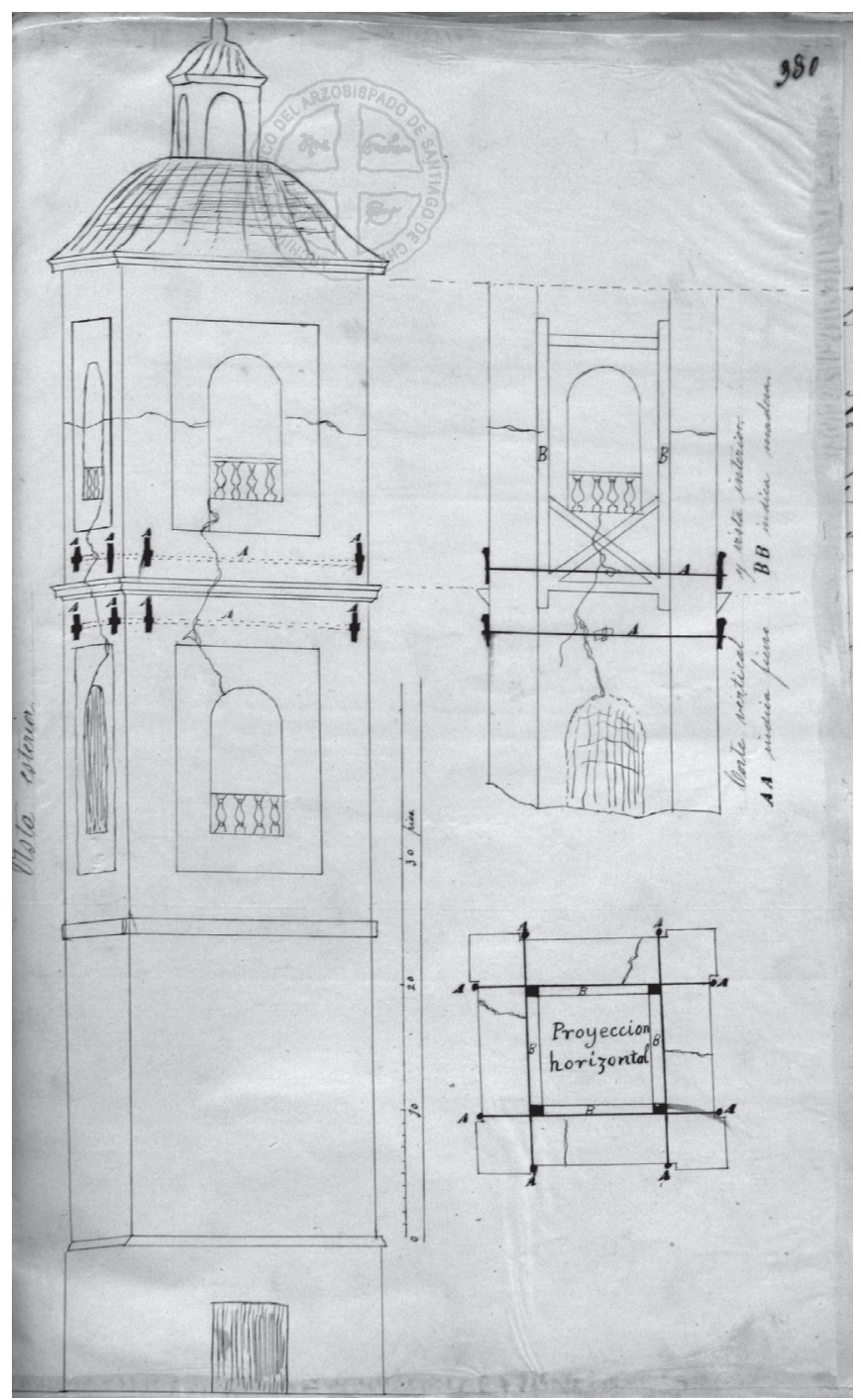

Figura 12. Croquis y planos torre Toesca atribuido a Fermín Vivaceta. Fuente: Archivo Arzobispal de Santiago, Fondo Gobierno, 27b/57a, enero, 1865. 


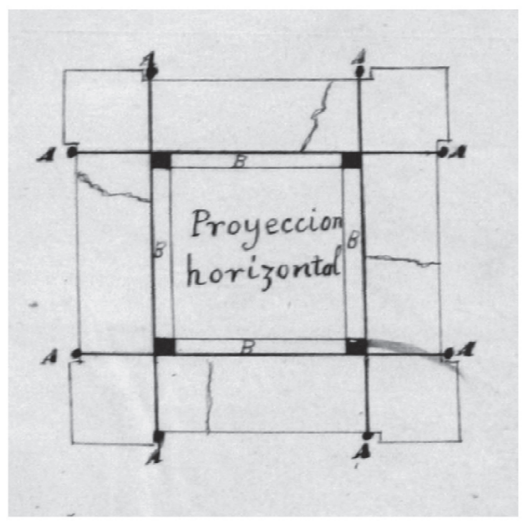

Figura 12a. Detalle de la planta de la torre de Toesca.

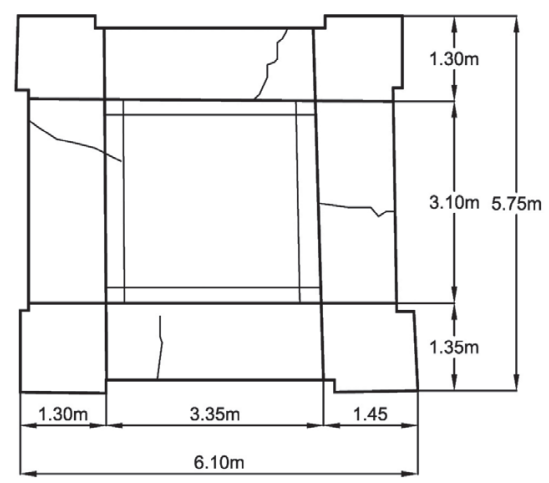

Figura 12b. Reconstrucción digitalizada de la planta basada en el Croquis de Vivaceta. Plano elaborado por Marco Barrientos, 2010 .

Además de las referencias iconográficas existentes que permiten determinar el emplazamiento de la torre, el croquis de su planta y elevación realizado por Fermín Vivaceta en 1865 constituye una valiosa fuente ${ }^{23}$. Dicho croquis corresponde a la propuesta que elabora este arquitecto para dar solución a los daños estructurales causados por los sismos, proporcionando información relativa a las dimensiones y materialidad (figs. 12, 12a y 12b), lo que ha permitido reelaborar digitalmente su planta e insertarla en el plano general de la manzana (fig. 13) ${ }^{24}$.

Otros aspectos de la torre se han recogido a partir de fuentes documentales, las que ofrecen mayores precisiones para la interpretación de algunas descripciones que relacionan la construcción de nuevas dependencias con la torre de Toesca ${ }^{25}$. En este sentido, la torre es un obstáculo que impide la prosecución de las obras y ampliaciones destinadas a oficinas (figs. 13 y 14).

Por otra parte, en el inventario de 1874 se menciona la existencia de "una torre aislada de cal y canto, que contiene las seis campanas de la Catedral: tres grandes y tres más pequeñas" 26 . Esta breve referencia plantea dos cuestiones de suma importancia. Por un lado describe la torre como una construcción aislada, es decir, que carecía de construcciones adosadas y, por otro, que esta se emplazaba en un terreno perteneciente a la Catedral y no al Palacio Arzobispal. Posteriormente, en 1888, el Arzobispado edificará en un terreno contiguo al Palacio una vivienda destinada

23 AA, Fondo Gobierno, legajo 27b/57a, 23 de enero de 1865.

24 Este croquis ha sido analizado por F. Ducci en "Las torres de la catedral: la vertical incorporada a la horizontalidad del nuevo edificio", trabajo realizado en el seminario de investigación dirigido por Fernando Pérez, Escuela de Arquitectura, Pontificia Universidad Católica de Chile, diciembre, 1998.

25 AC, Inventario,1874, op. cit., e Inventario..., 1875, op. cit.

26 AC, Inventario, 1874, op. cit. 
al obispo y su familia (fig. 15, letra J). Este edificio pondrá de manifiesto la complejidad en la demarcación de los límites de las propiedades de dos de las entidades que están actuando en esta parte de la manzana: el Arzobispado y la Catedral (figs. 15 y 16), debido a que se emplaza en parte de los terrenos que estaban asociados a la fábrica ${ }^{27}$.

Un mes después de la demolición de la torre en 1875, Juan Murphy elaboró un cuadernillo de especificaciones para un proyecto al interior de la manzana. El subtítulo es elocuente: "Explicaciones sobre la construcción del Edificio proyectado para el patio entre Catedrale, Sacrario y Palacio arzobispal". La directa referencia a las oficinas que se ubicarían entre estos tres edificios permite sugerir que se trata de una construcción que debiera estar emplazada en el corazón de la manzana. El texto contiene especificaciones de materiales e indicaciones para la construcción de una serie de obras, donde se menciona que "[...] la destrucción de la torre vieja como el edificio actual tiene que encargarse al constructor con el derecho de emplear en la nueva construcción lo que permita el director del trabajo, por ejemplo piedras, ladrillos, adobes, maderas [...]"28.

Se expresa aquí una relación entre la destrucción de la torre "vieja", es decir, la torre proyectada por Toesca, y la construcción de una nueva edificación. Se deduce entonces que hay un proyecto que abarca ambas faenas: la demolición de un edificio y la construcción de uno nuevo.

Adicionalmente, en un inventario de la Catedral de 1895, se hace referencia a un edificio de doble crujía, que está ubicado de norte a sur:

“[...] los el cañón doble que corre de norte a sur, la parte alta que da al patio de la Iglesia está destinada al Sacristán Mayor y la baja a [...] para útiles de la Iglesia.

La parte que corresponde al patio de la Capilla del Sagrario tiene en alto piezas, para habitación del Sr. Cura; y en la baja un salón para reuniones: una pieza para el archivo parroquial y otra para el Sacristán. Estos dos patios están separados por una reja de fierro en la parte alta y por tres en la parte baja" 29 .

Se propone que tal descripción corresponde al edificio de dos pisos que separa el patio del Sagrario del patio de la Catedral. La alusión al doble cañón corresponde a una doble crujía que es posible visualizar en la única construcción con estas características en dicho patio (fig. 15, L y K). Adicionalmente se describen las rejas de fierro que separan ambos patios (fig. 15, p1).

27 La propiedad de la Iglesia al interior de la manzana era compartida entre tres entidades eclesiásticas que actuaban como personas jurídicas, sujetas a derechos y deberes ante la ley civil y canónica: el Cabildo Metropolitano, propietario de la Catedral y sus dependencias, cuyo representante legal era el deán (uno de los canónigos que integraban dicha corporación); el Arzobispado o Mitra, una segunda persona jurídica que poseía bienes de la Iglesia y que tenía colaboradores directos en la conducción de la diócesis, formando parte de la curia diocesana, cuyo representante legal era el arzobispo; y la Parroquia del Sagrario, persona jurídica cuyo representante legal era el párroco.

28 AC, Cuadernillo explicativo para el edificio que se va a construir en el patio de la Catedral, Juan Murphy, 1 de noviembre, 1875.

29 AC, Libro de Inventario. Año 1895. Inventario de los bienes que están inmediatamente a cargo del Sacristán Mayor, 1895. 
El inventario de 1875, en tanto, realizado meses antes de la demolición de la torre de Toesca, da cuenta de los límites de la propiedad de la Catedral, señalando que en el costado sur "[...] el terreno es ahora más irregular que en marzo de 1875”. Según este, el terreno de la Iglesia no tenía por lado otra irregularidad que la que provenía de internarse en ella el terreno de las casas de los señores Campino y Echeverría, diecinueve metros (fig. 15, vértices b-o) ${ }^{30}$. Tales eran propiedades seculares ubicadas hacia la calle Compañía, vecina al costado poniente del Palacio y ubicada en la esquina de Compañía con Bandera, colindante con las sacristías de la Catedral en el frente occidental, respectivamente. En relación al costado norte el documento señala:

“[...] Ahora esa misma internación la hace el Palacio con el nuevo edificio allí construido para la familia de los Arzobispos, hasta tocar con el patio de la Capilla del Sagrario, quedando al sur de esa línea una pieza para los Sacristanes del Sagrario, en donde estuvo la torre que se demolió para edificar la que ahora existe sobre el edificio del Sagrario" 31 .

A partir de la década de 1870 , la manzana ya cuenta con sus principales edificios consolidados formalmente, con la fachada eclesiástica constituida en todo su frente hacia la Plaza de Armas, y en el interior se ha dado inicio al proceso de densificación. Se trata de un fenómeno que se alinea con el sostenido y gradual crecimiento de la Iglesia como institución y que busca responder a las crecientes necesidades administrativas, mediante la construcción de edificios cuyas constantes limitaciones fueron los problemas de espacio y la falta de recursos. La estrechez de presupuesto no podía más que perpetuar el desarrollo de este fenómeno de expansión en forma espontánea y poco planificada.

\section{LAS CONSTRUCCIONES AL INTERIOR DE LA MANZANA}

Las diferencias entre el mundo civil y el mundo eclesiástico marcaron el acontecer político y cultural a partir de mediados del siglo XIX. El denominado debate clerical-anticlerical había puesto en la agenda temas como la laicización del sistema educacional, la secularización de los cementerios, el matrimonio civil y, finalmente, la separación de la Iglesia del Estado. Según Sol Serrano, este proceso se debe entender en el marco de una Iglesia y un Estado que se están construyendo y de una Iglesia que aparece como un conjunto de cuerpos con muchas autonomías, que la jerarquización diocesana apenas puede administrar ${ }^{32}$. Se trata de un fenómeno más amplio en el que el Estado se seculariza, la religión se inserta en la sociedad civil y la Iglesia se expande institucionalmente ${ }^{33}$.

\footnotetext{
$30 \quad$ Idem.

31 Idem.

32 Sol Serrano, ¿Qué hacer con Dios en la República? Política y secularización en Chile (18451885), Santiago, Fondo de Cultura Económica, 2008, 24.

33 Ibid., 25.
} 


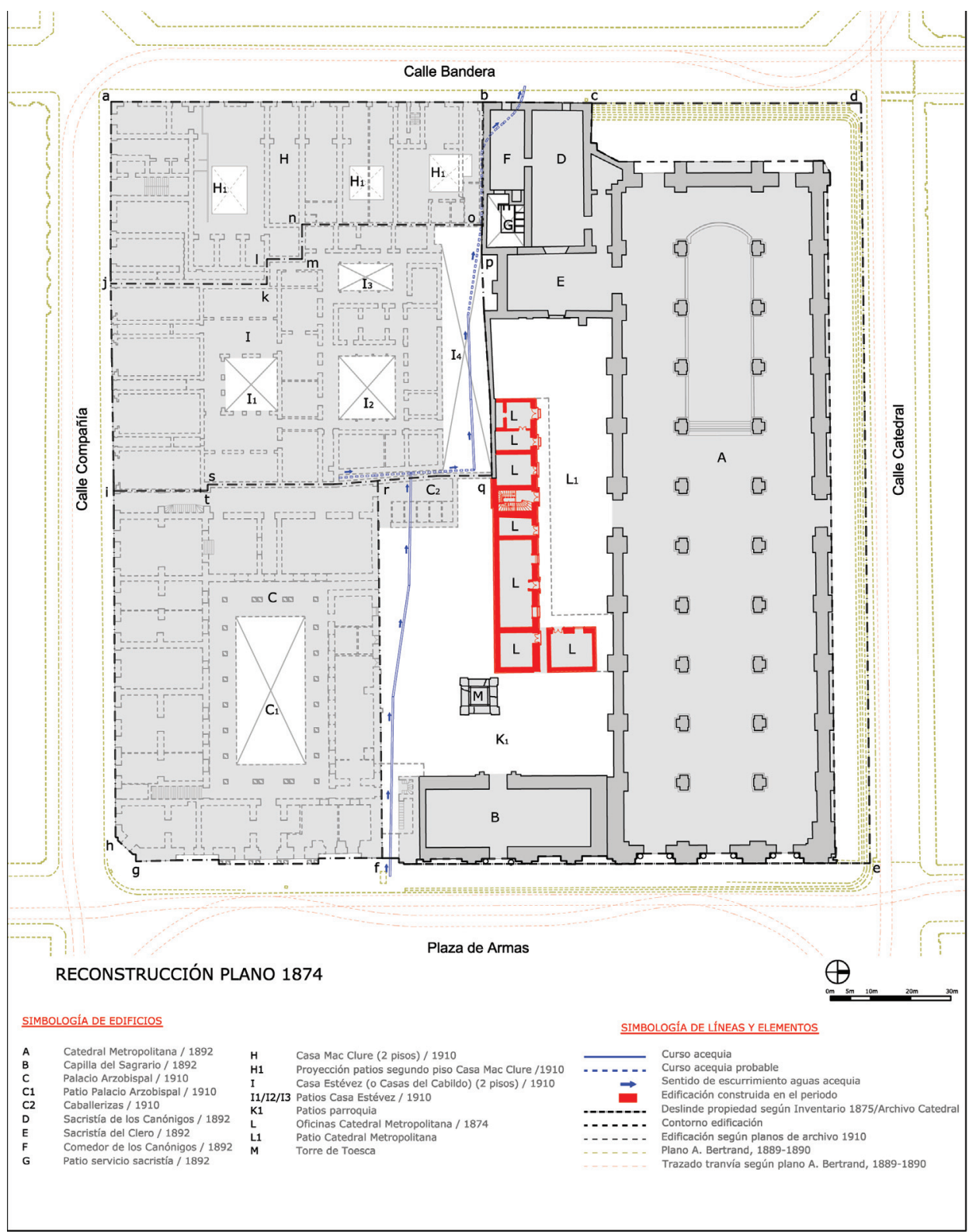

Figura 13. Reconstrucción de la planta de la manzana, 1874. Plano elaborado por Marco Barrientos, 2010 . 


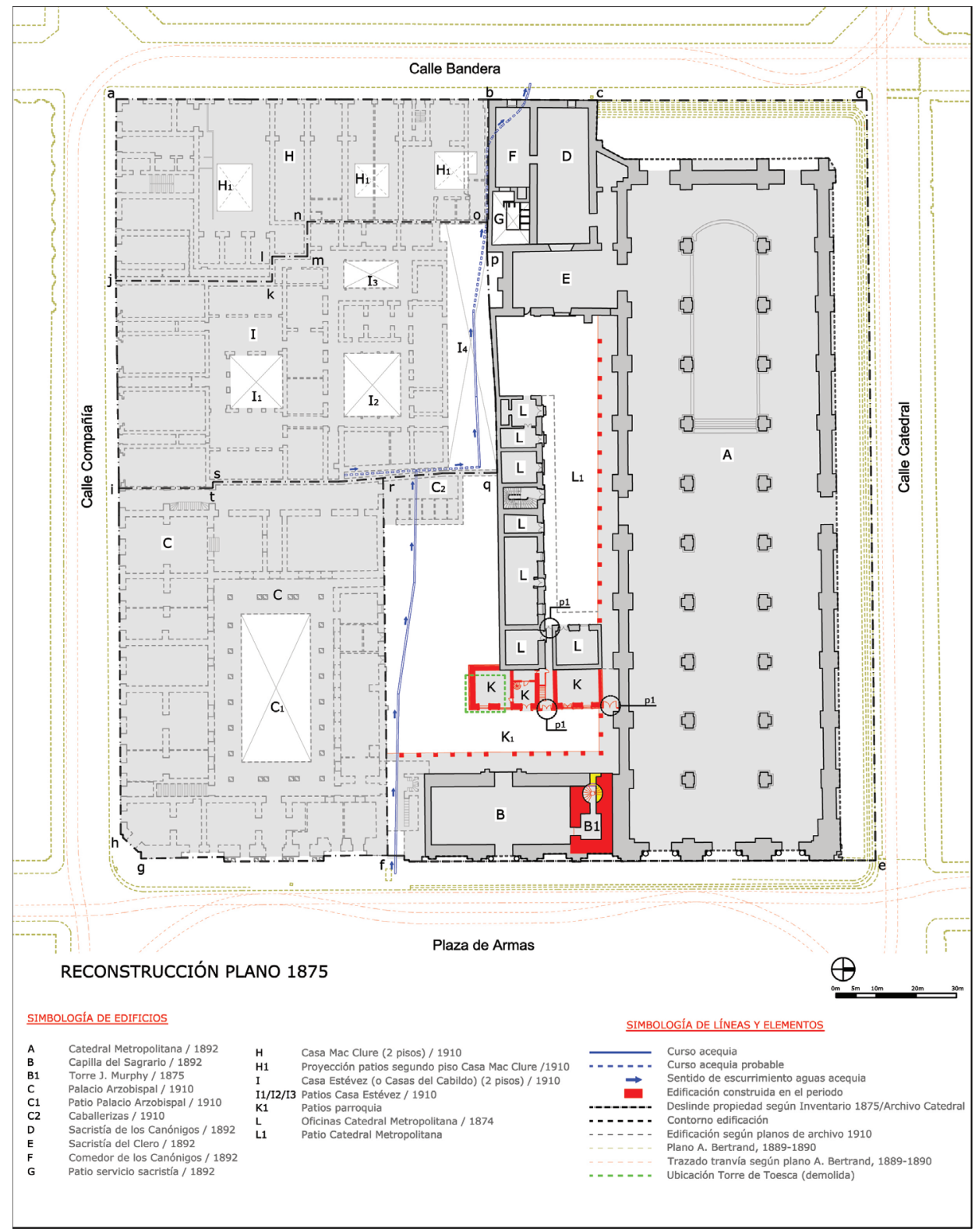

Figura 14. Reconstrucción de la planta de la manzana, 1875. Plano elaborado por Marco Barrientos, 2010. 
Al clima de tensión que generó la discusión de estos temas se sumó el rechazo de la Santa Sede ante la nominación del prebendado Francisco de Paula Taforó, propuesto por el gobierno del presidente Santa María para ocupar la silla arzobispal de Santiago, vacante desde la muerte del arzobispo Rafael Valentín Valdivieso $^{34}$. Desde el punto de vista de las relaciones entre el poder civil y la Iglesia, las que hubo entre las distintas entidades eclesiásticas de la manzana de la catedral Cabildo Metropolitano, Arzobispado y Parroquia del Sagrario- no fueron menos complicadas.

Por largo tiempo estas estuvieron marcadas por las disputas legales entre el Arzobispado y el Cabildo Metropolitano por la propiedad sobre el Palacio Arzobispal, motivadas, entre otras cosas, por los derechos en la obtención del canon de arriendo de los locales comerciales del primer piso, los que representaban importantes ingresos a los fondos de la Iglesia. La Parroquia del Sagrario, en tanto, pese a gozar de total autonomía e independencia respecto del Cabildo Metropolitano (propietario de los edificios parroquiales), tuvo algunas tensiones de índole cotidiana, como el uso de las campanas de la torre que compartían ambos templos ${ }^{35}$. No obstante, más allá de ser este un hecho doméstico, lo que expresa es una tensión entre el administrador de los bienes de la iglesia y la sede parroquial, cuya jurisdicción se limita al aspecto administrativo.

Entre 1878 -año en que falleció el arzobispo Valdivieso- y 1886, la Sede Arzobispal estuvo vacante. Las decisiones quedaron interinamente en manos del Ecónomo de la Mitra. No obstante, durante este período se desarrollaron importantes proyectos y construcciones al interior de la manzana, que aumentaron su densificación, alcanzando un alto grado de saturación en la ocupación del suelo disponible.

De acuerdo a las fuentes documentales consultadas, en 1884 el arquitecto Ángel Agustín Herrera habría construido el edificio correspondiente a la sala capitular y a una pequeña sala anexa, proyecto que había quedado postergado en 1875 (fig. 16, L2 y L3). Si bien estas dos construcciones no representaron una mayor superficie edificada, resultan relevantes desde el punto de vista morfológico, por cuanto completaron la crujía de oriente a poniente y regularizaron los bordes del patio de la catedral (fig. 15). Resulta de especial interés el leve, aunque notorio, desalineamiento del deslinde sur que presenta este cuerpo (fig. 16, vértices p-q), cuestión derivada aparentemente de la preexistencia de la acequia que corría de oriente a poniente de forma irregular (fig. 4). Este hecho quedó consignado en un documento que daba por concluidos los trabajos de Herrera, señalando que "[...] el edificio no ha quedado bien alineado con el antiguo, por que el terreno era mas ancho en esa parte, i según dice el constructor, lo hizo presente al hacer los cimientos" 36 .

34 Este hecho fue determinante en la decisión del gobierno chileno de suspender las relaciones diplomáticas con la Santa Sede a principios de 1883, las que no se reanudarán hasta los inicios del gobierno de José Manuel Balmaceda (1886), quien propone al obispo Mariano Casanova como sucesor, recibiendo el beneplácito del Partido Conservador, del alto clero y, finalmente, del Vaticano. Ricardo Donoso, Las ideas políticas en Chile, México, Fondo de Cultura Económica, 1946.

35 AA, Fondo Gobierno, legajo 27, n 43, sin fecha, año 1880.

36 AA, Fondo Gobierno, legajo $27, \mathrm{n}^{\circ} 21,9$ de junio, 1884 
Con esta operación, el patio de la catedral quedaba constituido en sus cuatro bordes por una crujía de oficinas en dos pisos por el costado sur; por la fachada la Catedral, por el costado norte; y por las oficinas y la sacristía del clero por los costados oriente y poniente respectivamente.

Desde el punto de vista de la ocupación de la manzana, el hecho más significativo fue la mencionada construcción de la vivienda destinada al obispo de turno y su familia (fig. 16, J, J1 y J2). Este proyecto fue gestionado por el Ecónomo de la Mitra, Venancio Villalón, quien tras un informe relacionado con el estado del muro del costado norte del Palacio Arzobispal decide iniciar esta nueva obra. En relación al mencionado muro este informe indicaba que

“[...] se ha desaplomado, principalmente por la influencia de la acequia que corre paralela con ella; y por lo que se ha sumergido ha sido arrastrado el envigado entre altos i bajos, que ha dado por multado el desplome de las columnas del corredor del segundo piso donde actualmente existen oficinas de la Comisión de Cuentas Diocesanas [...]

Habiéndose sumergido la antedicha muralla por el motivo indicado, y encontrándose la muralla que dá al patio de dicho Palacio en buen estado, ha influido el peso de la muralla del segundo piso sobre la del costado norte que da al lado de la Catedral, que el envigado ha servido de palanca para desplomar la columnata de la baranda" ${ }^{37}$.

El mal estado del muro, sumado a la necesidad de dar un mejor uso al Palacio, fueron determinantes para agilizar la construcción de la casa del obispo. En la opinión de algunos expertos, convenía demoler el muro en mal estado y fortalecer este costado del Palacio con un edificio que actuara como refuerzo estructural perpendicularmente al plomo dañado, adosándose en parte a la crujía norte del Palacio. Se sugiere que, de los edificios,

“el primero [fig. 16, letra J oriente] sea una prolongación del que existe en el primer patio de la catedral; el segundo, [fig. 16, letra J poniente] paralelo al primero, y que atraviese el sitio que estaba desocupado. De ese modo, la construcción de esos dos edificios evitaría la destrucción de la muralla que estaba deteriorada" 38 .

Estos dos edificios mencionados corresponden a las dos crujías de las casas del obispo, que junto con las caballerizas del fondo del sitio conformarán dos patios intermedios. Al adosarse estos cuerpos perpendiculares al muro norte, se refuerzan los muros debilitados, evitando así su derrumbe. El informe agrega además que la muralla que daba al frente de la iglesia del Sagrario sería estucada de igual forma que el edificio nuevo y las que daban a los patios serían retocadas, enlucidas y pintadas al óleo en la parte baja y alta. Ello suponía la preexistencia de un tramo de edificio frente al Sagrario, conformando parte del patio de este (fig. 16, K1).

Esta explicación se ve complementada con las descripciones del mismo Herrera en un presupuesto presentado para su construcción. En este documento detalla

37 AA, Fondo Gobierno, legajo 28, $\mathrm{n}^{\circ}$ 57, 5 de septiembre, 1885.

38 Idem. 
tanto la distribución de los recintos, como las características formales y la materialidad de los elementos arquitectónicos y constructivos, lo que permite inferir que se trata del mismo edificio ${ }^{39}$.

La casa del obispo constituye un complejo elemento en la manzana, debido a su emplazamiento, condición de edificio interior y por estar rodeado por un conjunto edificado y continuo ordenado en torno a patios. A su vez representa la culminación de un proceso de densificación que llena el último paño disponible para edificar nuevas construcciones al interior de la manzana.

Así, para fines de la década de 1880 , la manzana de la catedral se caracterizaba por su unidad morfológica (fachada continua y regularidad en las alturas de los edificios eclesiásticos). Pero en contraposición a estos rasgos formales exteriores, hacia el interior se ha tejido una compleja red de construcciones, patios y circulaciones agregadas de manera consecutiva.

\section{EXPANSIÓN DE LAS PROPIEDADES ECLESIÁSTICAS EN LA MANZANA}

Si la década anterior se concentró en la ocupación del interior de la manzana, a partir de 1894 comenzó un período de ajuste y redefinición de los deslindes de los terrenos. Dos hechos marcaron el incremento en forma sustancial la propiedad del Cabildo Metropolitano en la manzana: la adjudicación del Palacio Arzobispal en el pleito judicial que sostenía con el Arzobispado de Santiago, por un lado, y la adquisición de nuevas propiedades, por otro.

El litigio librado entre ambas instituciones de la Iglesia, que se arrastraba desde la década de 1840, fue resuelto en 1894 tras el dictamen de la Santa Sede que adjudicaba la propiedad del Palacio Arzobispal a la fábrica de la Iglesia Metropoli$\operatorname{tana}^{40}$. Con esta sentencia, la propiedad del Palacio pasó a ser del administrador de los bienes de la Catedral, es decir, el Cabildo Metropolitano (integrado por los canónigos y encabezado por el deán), en desmedro de las intenciones del Arzobispado. Y pese a que se establecieron algunas restricciones formales respecto al uso de ciertos recintos para el arzobispo, en la práctica, el propietario de los terrenos y de los edificios era el Cabildo Metropolitano ${ }^{41}$. Así, por ejemplo, se excluyen al uso y habitación del arzobispo "los edificios del piso inferior situados en el costado oriente, en el costado sur y en la parte del costado poniente que llega hasta el pasadizo marcado en el plano con la letra $\mathrm{D}$ de los cuales quedan perpetuamente destinados a ser arrendados" 42 (Fig. 2).

39 AA, Fondo Gobierno, legajo 52, $\mathrm{n}^{\circ}$ 14, 5 de octubre, 1886.

40 AC, Libros de actas y acuerdos 1894-1903, vol. 16, 6 noviembre, 1894.

41 Cabe destacar que en 1929 la propiedad del Palacio Arzobispal volvió a manos del Arzobispo a través de una operación de compra venta celebrada entre este y el Cabildo Metropolitano.Véase Retamal, op. cit, 1784-6.

42 Idem. El artículo II señala que, no obstante, continuará sirviendo a la curia eclesiástica la primera pieza del costado oriente, contigua a la puerta de la plaza que da entrada al patio de la capilla del Sagrario. Asimismo, quedará para el arzobispo la pieza en que está situada la escalera que conduce al segundo piso. 


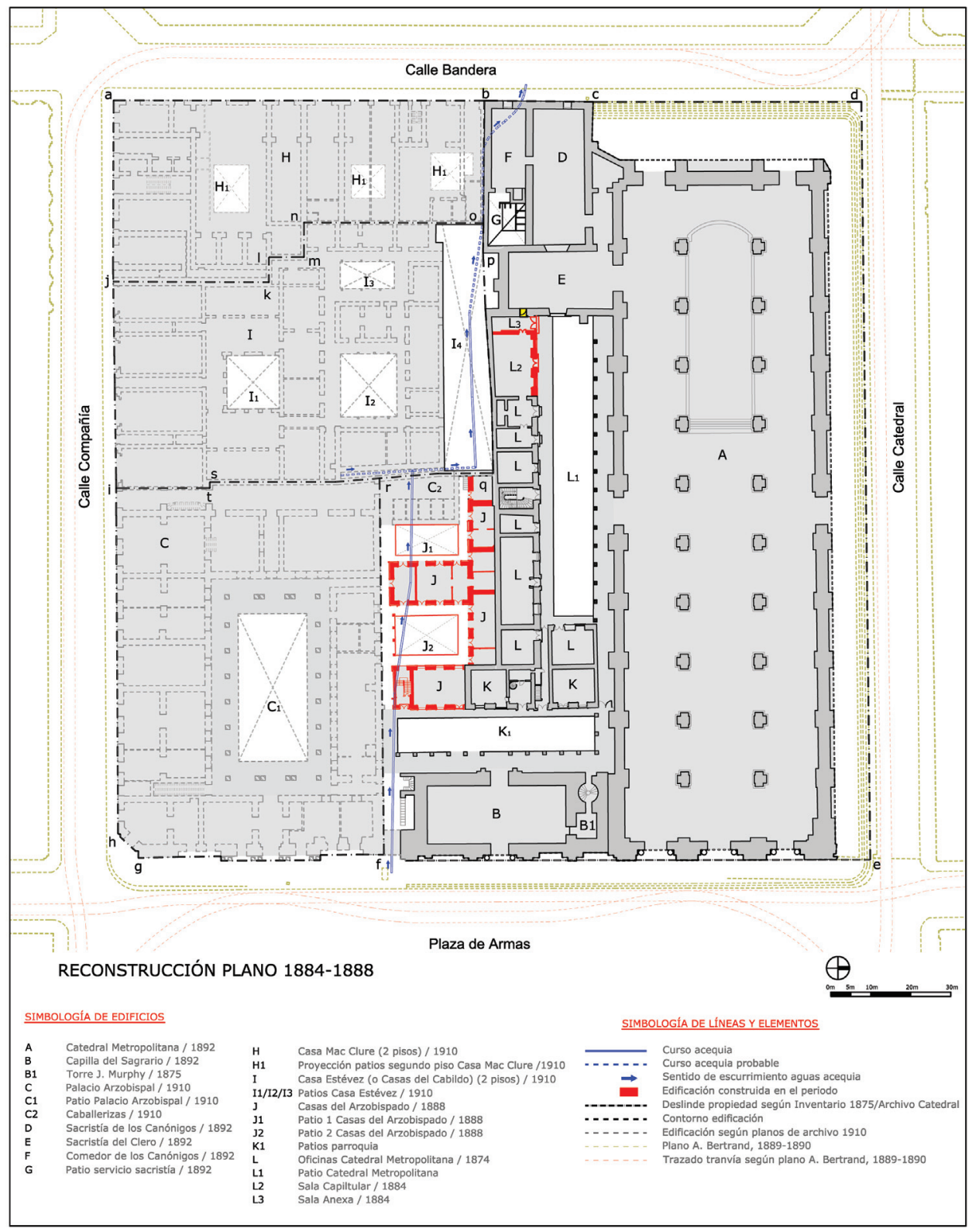

Figura 15. Reconstrucción de la planta de la manzana, 1884-1888. Plano elaborado por Marco Barrientos, 2010. 


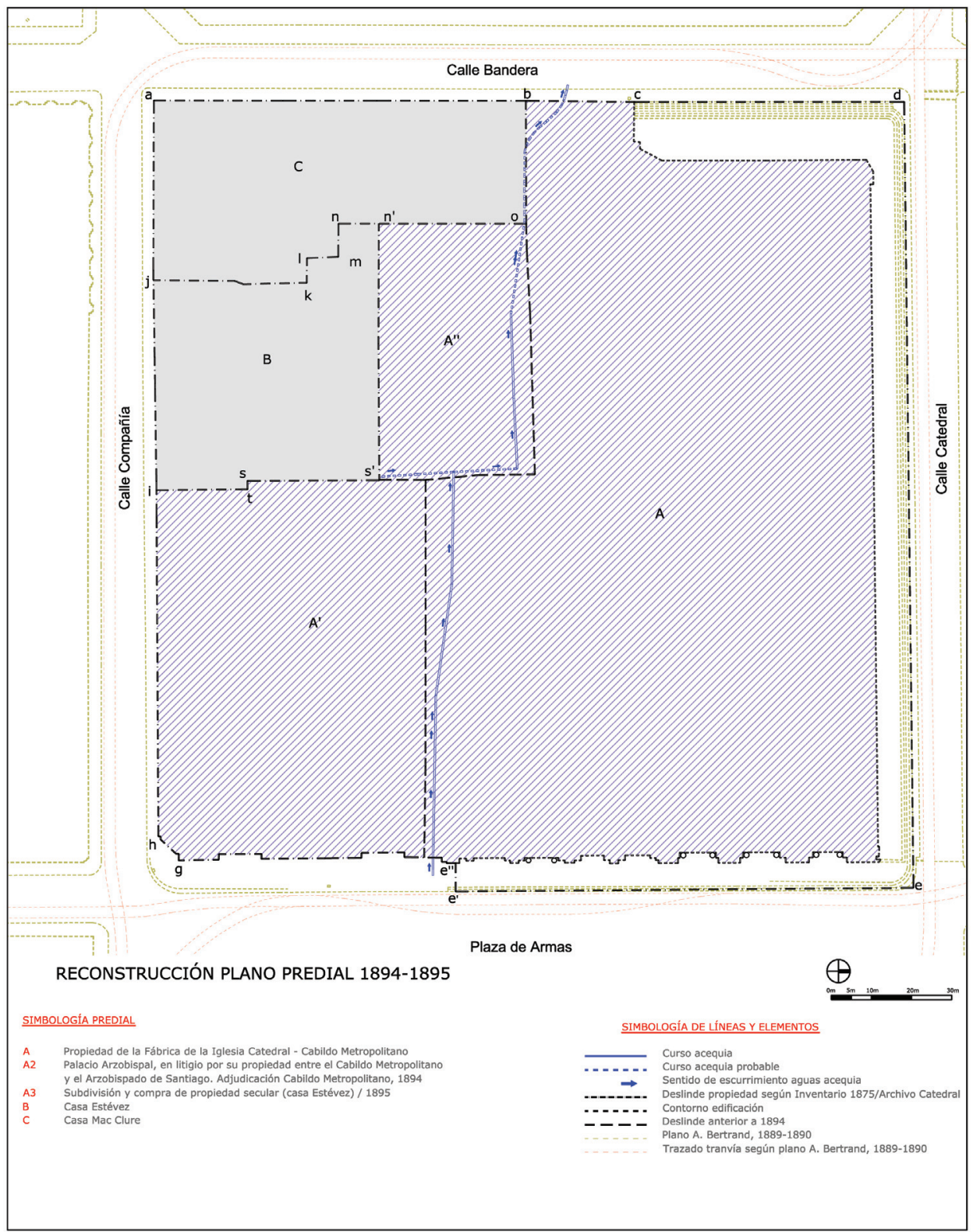

Figura 16. Reconstrucción de la planta predial de la manzana, 1894-1895. Plano elaborado por Marco Barrientos, 2010. 
La adjudicación del Palacio a las propiedades del Cabildo Metropolitano constituyó tan solo la primera de las operaciones que ampliarían su área de influencia en la manzana mediante la incorporación de propiedades seculares. En 1895, este adquirió cerca del $50 \%$ de la propiedad particular de Elena Gazmuri viuda de Estévez, que originalmente ocupaba cerca de un cuarto del frente por la calle Compañía y tenía una profundidad cercana a los 58,50 metros de fondo medio del sitio, hasta topar con la propiedad de la catedral (fig. 17, letras B/A'’)43. Esta operación supuso la subdivisión predial del lote primitivo, estableciéndose un nuevo deslinde entre esta propiedad particular y la Catedral.

De esta forma, se anexaba parte de la construcción existente, patios y la sección de la acequia que pasaba por el fondo del sitio. El acceso directo a la acequia solucionaba una serie de necesidades y problemas sanitarios para la habitación de los sacerdotes y servidumbre que habitaban en las dependencias de la Catedral.

La sección del edificio existente en esta compra contaba con recintos que fueron destinados a bodegas, a la biblioteca y a la administración del Cabildo ${ }^{44}$. También se anexaron los tres patios mencionados. Para poder delimitar la partición oriente poniente que subdividió esta propiedad, el contrato de compra venta exigía la construcción de un muro divisorio que coincidía con el muro estructural de una de la crujías de la vivienda (fig. 16), al cual se le agregaron los tramos que vinculaban con el paño sur restante de la propiedad, hasta la calle Compañía (fig. 18).

Esta acción del Cabildo Metropolitano refleja un primer avance en la expansión de su propiedad -junto con la mencionada adjudicación del Palacio Arzobispalpues expresa la voluntad de adquirir nuevas construcciones y aumentar su dominio en la manzana, lo que en la práctica se traduce en la redefinición de los deslindes y superficies de las propiedades. La contracción, en cambio, la sufren las propiedades seculares, que comienzan a ceder terreno frente a la extensión de la Iglesia.

Si se analiza el plano de deslindes de este período, se pueden apreciar algunos límites irregulares entre las propiedades. Los que separan al Palacio Arzobispal de la casa Estévez, y a su vez, la casa Estévez de la casa Mac Clure, presentan un trazado irregular caracterizado por un desarrollo "zigzagueante" y desalineado (fig. 16). Y aunque no se ha podido establecer las causas de este particular trazado, merece especial atención en cuanto difiere del esquema ordenador, simétrico y regular representado en el plano de Thayer Ojeda, constituyendo líneas prediales que subsisten hasta hoy.

43 En sesión ordinaria del 17 de septiembre de 1895, el Cabildo aprobó la compra de terrenos a doña Elena Gazmuri para ensanchar las pertenencias de la Iglesia Catedral a un costo de $\$ 100.000$. Se menciona que parte del dinero se obtendrá con la mitad de los arriendos del Palacio Arzobispal más los fondos generados por la Iglesia. Véase AC, Libros de actas y acuerdos 1894-1903, vol. 16, 75-86.

44 AC, Libros de actas y acuerdos 1894-1903, Acta de la sesión ordinaria del Cabildo con fecha 27 de agosto de 1895, vol. 16. Según el Inventario de 1895, los edificios existentes constaban de recintos para bodegas destinadas a guardar el vino y la cera, cuadros, alfombras, estatuas, el carbón, barriles y otros útiles, un recinto para la administración del Cabildo y otro para ser usado como biblioteca. 


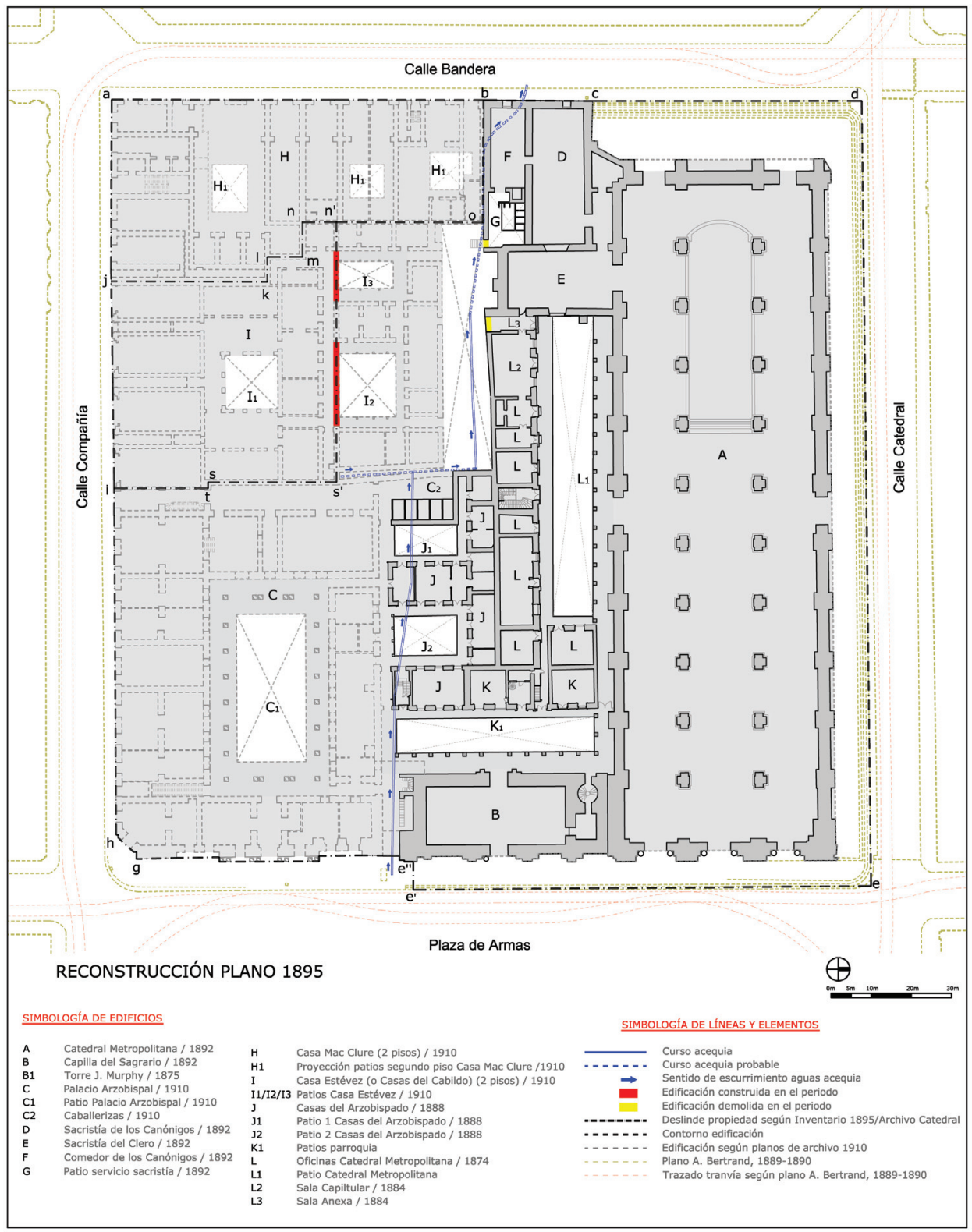

Figura 17. Reconstrucción de la planta predial de la manzana, 1894-1895. Plano elaborado por Marco Barrientos, 2010. 
Paralelamente a la expansión de la propiedad de la Iglesia en la manzana, la década de 1890 a 1900 estuvo marcada por la concreción de la tan anhelada refacción y terminación de la fábrica de la catedral. Tras un concurso para llevar a cabo tal refacción, se presentaron en 1897 dos propuestas. Una desarrollada por el arquitecto italiano Ignacio Cremonesi y la otra por el arquitecto francés Emilio Doyere, las que fueron evaluadas por una comisión de arquitectos nombrados por los miembros integrantes del Cabildo Metropolitano ${ }^{45}$. Parte de los requerimientos exigidos por la Iglesia era otorgar a las fachadas del templo un lenguaje formal acorde a la época, incorporar las dos torres que coronaran el frente principal, construir la cúpula sobre el altar mayor, erigir la capilla del Santísimo y ejecutar los arreglos necesarios en la capilla del Sagrario. Una vez evaluados ambos proyectos, los expertos y canónigos se inclinaron por la propuesta de Cremonesi. Correspondió al arzobispo Casanova concretar su contratación que, entre 1897 y 1903, dio origen a radicales intervenciones. El aspecto actual de la Iglesia y Sagrario corresponde en gran parte al proyecto original desarrollado por el italiano (fig. 18) ${ }^{46}$.

Tras esta serie de operaciones, que van desde cuestiones legales -la compra de propiedades-, jurídicas -la adjudicación del Palacio Arzobispal-, decisiones políticas por parte de la Iglesia -dictámenes eclesiásticos-, transformaciones a escala urbana -reflejadas en las estrategias y forma de densificación de la manzana-, hasta definiciones de la forma arquitectónica -intervención de los edificios en su interior y exterior-, el Cabildo Metropolitano había logrado consolidar un nivel de protagonismo e influencia en la ciudad que se refleja no solo en la ampliación de su propiedad sobre los terrenos de la manzana, sino también en la monumentalidad formal de los edificios que configuran la fachada poniente de la Plaza de Armas, otorgando por primera vez una unidad formal y espacial total del conjunto eclesiástico y, al mismo tiempo, respondiendo a las necesidades y requerimientos administrativos a través de los edificios emplazados en el interior de la manzana. Todas estas operaciones alcanzaron su apogeo en la siguiente década, cuando se daba inicio a la mayor transformación de la Catedral de Santiago.

\section{Auge DE LA PRESENCIA DE LA IGLESIA EN LA MANZANA}

En 1909 el Cabildo Metropolitano adquirió el resto de la propiedad de la denominada casa Estévez. Con esta operación, se incorporaba al patrimonio de la Catedral un valioso frente comercial (32,20 metros), que enfrentaba la calle Compañía y lograba acceder al fondo del sitio a través de la misma calle sin necesidad de una servidumbre.

45 AC, Libros de actas y acuerdos 1894-1903, vols. 14, 15, 16 y 17, notas inéditas de M. Angélica Delpiano.

46 Fernando Pérez Oyarzún, Roman modernization in Chile, texto inédito, 2009. 
Las notas del inventario de la Iglesia Metropolitana de 1913, aseguran que una de las razones más poderosas para realizar esta inversión fue precisamente el hecho de que esta permitiría a los patios interiores traseros dar salida a la calle Compañía y aumentar el ingreso de las rentas mediante el arriendo de los locales comerciales con frente a dicha calle ${ }^{47}$. Con esta nueva compra, la Catedral quedaba como propietaria casi única de la manzana, a excepción de la casa esquina de la calle Bandera con Compañía (la denominada casa Mac Clure). Este nuevo dominio de la Catedral representaba un valor cercano al $90 \%$ del total de la superficie de la manzana (fig. 16, letras A/A'/A'/B). Así, el año 1909 representa el momento cúlmine de influencia de la Iglesia sobre la manzana. Se trata de un momento único en la historia de la catedral, de su relación con la ciudad y la notable presencia urbana que culmina con el proyecto de Cremonesi. Mas a partir de 1930, comenzará un proceso de continuo y progresivo deterioro y obsolescencia, producto tanto del abandono de la ocupación de sus dependencias como del estado de conservación de sus edificios.

Y aunque la densificación de la manzana no concentró aumentos en la primera década del siglo XX, las transformaciones en su interior estuvieron marcadas en la realización de las alteraciones necesarias para conectar las distintas propiedades adquiridas. El gran desafío se centra en dar solución a una intrincada sumatoria de edificios de diversa índole, agregados en distintos períodos de tiempo y que, paulatinamente, debieron responder a las necesidades de conexión que exigían sus funciones.

Una de estas operaciones queda de manifiesto en las obras de demolición que tuvieron que realizarse para conectar las dos partes de la primitiva casa Estévez, llamada para este período Casas del Cabildo (fig. 17). Sobre el mismo muro que tuvo que edificar la catedral cuando compró el primer paño, tuvo que hacer "perforaciones" para generar los vanos necesarios para la comunicación con el resto de la propiedad comprada (fig. 18). Pero más allá de estas obras, la saturación de la densificación genera una serie de intrincadas circulaciones entre los distintos edificios, que actúan de forma autónoma, pero que requieren al mismo de tiempo de conectividades interiores, las que por lo general, estaban limitadas a pasillos o corredores y patios.

Del proyecto de Cremonesi, destaca la construcción de las dos torres que coronan la fachada oriente de la Catedral (fig. 18, núm. 1), la elevación de una cúpula sobre el penúltimo módulo de la nave central (fig. 18, núm. 2) y el alzamiento de las fachadas principales. En relación a los bordes exteriores del edificio de la Catedral, propuso un doble muro "adosado" a la fábrica de piedra existente, aumentando el espesor a nivel de zócalo en la fachada oriente, norte y poniente, con lo que consecuentemente se desplaza la línea de edificación. Adicionalmente, Cremonesi suprimió la franja de vereda con las gradas que rodeaban los mencionados costados, reemplazándola por una vereda de menor

$47 \mathrm{AC}$, Inventario de la Iglesia Metropolitana de Santiago de Chile. Inventario de los bienes que están inmediatamente a cargo del sacristán mayor, 1913. 
ancho y que desciende en forma paralela a la pendiente natural del terreno. La diferencia de altura que se alcanza en el costado poniente, se resuelve con la incorporación de dos gradas ubicadas en las puertas de las naves laterales norte y sur (fig. 18).

La ampliación del espacio de culto se aprecia en la conexión entre la Catedral y el Sagrario mediante una perforación -de 2,85 metros de espesor-que se realizó en ambos muros de sillería de piedra (fig. 18, núm. 5). La apertura de este vano implicó invertir la orientación del altar de la capilla, con lo que cambió el sentido de culto y la circulación entre la catedral y el Sagrario. Al mismo tiempo, se eliminó el segundo piso que había tenido hasta entonces la capilla y que se ocupaba como casa habitación del párroco y como salón de la Parroquia ${ }^{48}$.

$\mathrm{Al}$ interior de la Catedral, Cremonesi adosa una capilla que resuelve de manera definitiva la ansiada búsqueda de dar un espacio de culto al Santísimo Sacramento. El arquitecto propone edificarla en el muro sur, centrada en el séptimo intercolumnio, contiguo a la puerta que conectaba con el patio interior (fig. 18, $\mathrm{n}^{\circ} 3$ ). Tras esta operación, que dejaba dicho patio segregado en dos, se daba por concluido otro de los temas recurrentes del culto y de los edificios requeridos para cumplir con los oficios (fig. 18, L1 oriente y poniente).

Como respuesta a las demandas administrativas de la Iglesia y a la insuficiencia de espacio para ello, se amplía la sacristía del clero en seis metros hacia el costado sur (fig. 18, $\mathrm{n}^{\circ} 4$ ). Uno de los contratos de Cremonesi y las actas del Cabildo sugieren que esta ampliación tuvo alguna relación con la intención de colocar allí una caja de fondos para salvaguardar objetos de valor y documentos $^{49}$. El avance de la sacristía hacia el sur redefinía los nuevos límites de la propiedad de la Iglesia, consolidando un nuevo borde construido entre la casa Estévez y la Catedral.

Tras este período, la Catedral venderá gran parte de la superficie correspondiente a las Casas del Cabildo, ex casa Estévez, reservando para sí el patio (fig. 18, I4) además del pasaje que dividía dicha propiedad con el Palacio Arzobispal.

De este modo, hacia 1910, y luego de un largo proceso de construcción y unificación, las obras en torno al conjunto eclesiástico en su totalidad, es decir, tanto en sus edificios monumentales exteriores -Catedral, Palacio, Parroquiacomo en los interiores, se han consolidado en el paisaje urbano proyectando una imagen unitaria, formalmente compacta, homogénea y con un lenguaje arquitectónico representativo de la época.

La Iglesia se alineaba así con la modernización de la ciudad y con las celebraciones del primer centenario de la República, reflejando un grado de armonía y magnificencia en la manzana y que hicieron merecer su "reinauguración" en 1906 .

48 La discusión sobre la conexión se venía dando desde hacía algunas décadas, a raíz de un proyecto de ubicar allí el culto al Santísimo Sacramento. Véase AC, Libros de actas y acuerdos 18941903, op. cit., vols. 14, 15, 16 y 17.

49 AA, Fondo Gobierno, legajo $27 \mathrm{n}^{\circ}$ 57, Contratos de Don Ignacio Cremonesi para su refacción, 1903. 


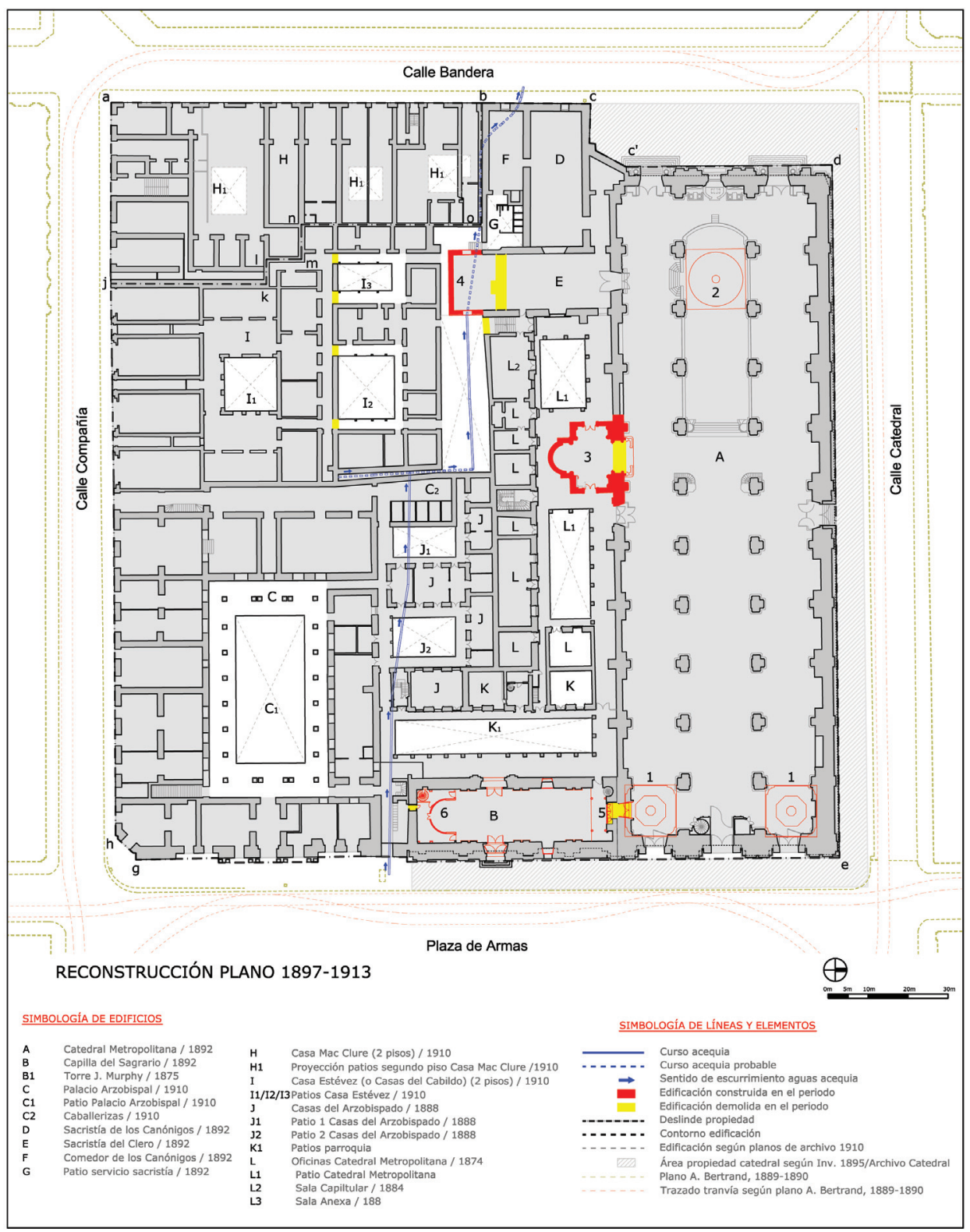

Figura 18. Reconstrucción de la planta de la manzana, 1897-1913. Plano elaborado por Marco Barrientos, 2010. 


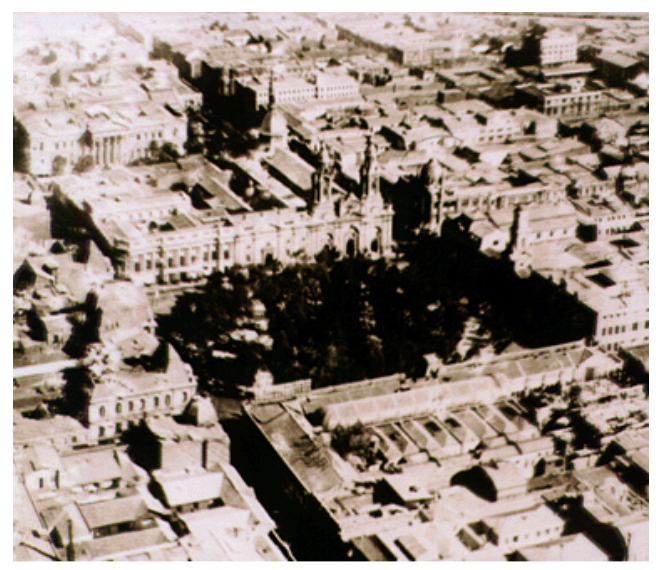

Figura 19. Vista panorámica de Plaza de Armas y de la manzana de la Catedral hacia 1910. Fuente: Cristóbal Dagnino, Centro ecuménico en la manzana de la Catedral Metropolitana de Santiago: reconstrucción del interior del conjunto Central Metropolitano, Parroquia del Sagrario, Palacio Episcopal, Santiago, Ediciones Universidad Católica de Chile, 2005.

\section{CONCLUSIONES}

En este estudio se han examinado una serie de transformaciones, a distintas escalas y grados de complejidad, en torno a la manzana de la Catedral. La convergencia entre factores externos que se reflejaron en las transformaciones sucedidas en la ciudad y factores internos, tales como las complejas relaciones y necesidades de la propia Iglesia y sus corporaciones, influyeron en los derroteros que derivaron tanto en la transformación morfológica de la manzana como en la obsolescencia de ciertos elementos de infraestructura urbana que fueron reemplazados por un nuevo orden que marcará a la ciudad de inicios del siglo XX.

El fenómeno de expansión y contracción morfológica se ha estudiado a partir del análisis de las propiedades y los edificios de la manzana en tres dimensiones. La primera estuvo relacionada con la flexibilidad o "ajuste" de los contornos de la edificación y cómo se manifestaron en una tensión de contracción y regularización de los bordes del edificio y de la vereda de la manzana. Asimismo, los deslindes que separan las propiedades en el interior variaron de acuerdo a las operaciones de compra y venta, a las subdivisiones de los solares y a las fusiones o anexiones de terrenos. Adicionalmente, este nivel de análisis se ha relacionado con el curso de las acequias (infraestructura sanitaria colonial), las cuales, por lo general, corrían paralelas a los límites prediales.

Una segunda dimensión de este análisis se relacionó con la densificación o grado de ocupación de la superficie en el interior de la manzana, fenómeno que alcanza en este período un alto grado de concentración. Esta dinámica de ocupación se ordena en base a la adición de construcciones organizadas en torno a patios, las que paulatinamente fueron tejiendo una compleja red de circulaciones y conexiones que otorgaron un rasgo "laberíntico" a esta manzana. 
La tercera aproximación para comprender el fenómeno de expansión y contracción se refirió a las construcciones. Además de las tres piezas principales de la manzana -Catedral, Palacio y Sagrario-, en este período se fueron agregando otras construcciones menores. Tras un proceso de revisión crítica a la luz de los diversos antecedentes, se representaron en una serie de planos las diversas alteraciones, demoliciones y nuevas edificaciones agregadas, así como la correspondiente redefinición de los deslindes.

Si este estudio ha abordado las particularidades de la manzana de la Catedral, también ha esbozado algunas relaciones que permiten orientar la discusión a la evolución de otras manzanas fundacionales. La complejidad del estudio de este caso particular radica en el conjunto de relaciones entre los estamentos religiosos, políticos, sociales y culturales que, a partir de la segunda mitad del siglo XIX, contribuyen al agotamiento de un orden de ciudad. Pese a que la manzana de la Catedral goza de una serie de rasgos exclusivos que la hacen única del resto del conjunto de manzanas en Santiago (coexistencia de propietarios del mundo religioso y secular; la presencia del templo más importante de la ciudad y sus edificios anexos y el emplazamiento estratégico en el núcleo fundacional), esta fue permeable a la influencia de los procesos urbanos que se desarrollaron en Santiago.

El fenómeno de expansión y contracción urbana se debe entender en relación al trazado fundacional de Santiago y al modelo de urbanización implantado en el territorio, basado en el orden reticular del damero. Este se vio sometido a una serie de fuerzas que modelaron diversas formas, tanto en su matriz original como en los cuerpos construidos sobre esta. A partir de este primer trazado ordenador, la manzana de la Catedral, al igual que otras, fue dividida en cuatro solares teóricamente iguales y atravesada de oriente a poniente por el curso de una acequia. Desde este esquema simple y simétrico, se comenzó un lento y progresivo proceso de complejización que se manifestó tanto en las subdivisiones y fusiones prediales, como en las alteraciones de los cursos de las acequias y en la construcción de los edificios que lentamente fueron llenando los vacíos de la manzana, dando origen a un esquema irregular, asimétrico y jerarquizado. En efecto, la variación experimentada entre los deslindes de las propiedades alcanzará un nivel de complejidad tal que dista mucho de aquel primer esquema elaborado por Tomás Thayer Ojeda, en el cual representa la fundación de Santiago en 1541 (fig. 1).

El crecimiento de la ciudad "empujó" la estructura del trazado fundacional a un estado crítico: la infraestructura urbana sufrió una importante y radical transformación derivada de la precariedad y obsolescencia de sus antiguos sistemas, lo que llevó al reemplazo del sistema de acequias por una red sanitaria más moderna y que evitaba atravesar las manzanas y sus complejas divisiones prediales, haciéndola más eficiente. Paralelamente, se comienza un sistemático reemplazo de las tipologías de edificios que comienzan a surgir en el siglo XX, lo que afectará de manera general a las construcciones del centro de Santiago y en especial a la manzana en estudio. Esta quedará inmersa en la dinámica de crecimiento y densificación urbana, lo que traerá como consecuencia el surgimiento de nuevas tipologías edificatorias, tales como edificios aislados, conjuntos y edificios adosados en altura. 
Así, mientras la construcción colonial primaria con edificios de uno o dos pisos ordenados en torno a patios será reemplazada por edificios de mayor altura y con un lenguaje arquitectónico más elaborado, el interior de la manzana se densificará progresivamente, compartimentando el gran vacío inicial, y derivará en la agregación de edificios que irán rellenando el corazón de la manzana hasta saturar todas las áreas disponibles.

Se trata de una fragmentación morfológica que deriva en una ruptura irreversible de la unidad de la manzana. Este fenómeno se desarrolla tanto en propiedades tradicionalmente seculares (esquina de Bandera con Compañía), como en propiedades que la iglesia fue liberando por medio de ventas a particulares, siguiendo así caminos muy distintos al resto del conjunto eclesiástico.

La incorporación de pasajes en el centro de Santiago y en la propia manzana de la catedral originará una nueva forma de ocupación en el sistema de circulación de la misma que rompe el primitivo orden colonial. En este contexto, la venta de la propiedad de las Casas del Cabildo en 1895 permite explicar la aparición del llamado "callejón", como pasaje abierto que penetra al interior por el costado poniente del Palacio Arzobispal.

Como consecuencia del reemplazo de tipologías edilicias, las líneas de la edificación sufrirán el retranqueo de sus bordes. Esta fuerza de contracción de la manzana significará la pérdida de considerables superficies de las propiedades en beneficio del espacio público, y se traducirá en el posterior ensanche de calles y veredas y en la rectificación de los nuevos contornos.

Paralelamente a los cambios ocurridos al interior de la manzana, se iniciaba en sus bordes una consolidación formal que, además de actuar como contenedora o "escudo" del proceso interior, terminará siendo representativa de una de las fachadas más notables de la ciudad.

El proceso de transformación de la manzana estuvo también determinado por los propios cambios que la Iglesia experimentó como institución. El paso de una modesta diócesis a una arquidiócesis con mayor relevancia se hizo coincidente con una mayor complejidad de sus funciones. Esto significó la demanda concreta por incrementar sus edificios para atender al culto y su propia administración y se vio reflejado en la ocupación interior de la manzana. Naturalmente, esto fue posible gracias a la expansión de su dominio dentro de la manzana, lo cual revelaba una mayor presencia de la institución hacia 1910.

Se ha podido establecer que tanto el fenómeno de expansión y contracción urbana como la construcción e intervención en las distintas piezas de la manzana, lejos de constituir un proceso de planificación a gran escala, consistió en una serie de operaciones que fueron respondiendo a las necesidades prácticas y de culto de la Iglesia. De alguna forma, la agregación orgánica de los distintos elementos en la manzana fue el resultado de una sumatoria de intervenciones más que de un plan maestro que concibiera la manzana de la catedral como un cuerpo unitario y coherente entre las partes del conjunto eclesiástico y los templos ahí emplazados.

Para fines de 1910, el fenómeno de expansión y contracción urbana alcanzaba un momento crítico que representaba el fin de un orden urbano que pervivía desde 
los orígenes de la ciudad y que, tras el desarrollo y crecimiento de la misma, se reconfiguraba como un nuevo soporte de la ciudad moderna. Así y todo, como en el resto de las manzanas, perviven en su desarrollo elementos que la acompañan desde sus inicios y que van desde la partición inicial hasta elementos físicos que permanecen, tales como sus antiguas acequias, aun cuando hayan perdido vigencia.

Los tres edificios monumentales y emblemáticos de la manzana -la Catedral metropolitana, la Parroquia del Sagrario y el Palacio Arzobispal- se fueron consolidando paulatinamente y constituyendo como cuerpos compactos, rígidos, unitarios en su aspecto formal y con un carácter arquitectónico rotundo. Sin embargo, a la luz de las revisiones y análisis desarrollados en este trabajo, se ha constatado que estos fueron permeables a factores sociales y políticos, a los propios cambios de la institución, a las diversas influencias urbanas y a las continuas transformaciones edificatorias. Todos estos procesos se cristalizan en estos tres edificios, los cuales acumulan múltiples capas representativas de diversas etapas históricas y arquitectónicas. 
